International Journal of Kurdish Studies

(ISSN:2149-2751)

2 (3), pp. $196-208$

http://www.ijoks.com

\title{
The impact of the power struggle in the Renaissance delayed national thought in South Kurdistan 1800-1850
}

\author{
Mohammed Ahmed Ibrahim Galalaye ${ }^{I}$
}

Received: April 17, 2016

Reviewed: May 13, 2016

Accepted: May 22, 2016

\begin{abstract}
The national thought of Kurdish renaissance has been delayed due to long term conflicts among Kurdish Emirates, in particular in the first half of the $19^{\text {th }}$ century. Along with other nations under Ottoman Empire and its renaissancebeginning in 1839 and later years by Sultan Abdul-Majeed while Kurdish society was encountering backwardness, subordinate in policy, economy and education aspects. Consisting first half of the $19^{\text {th }}$ century, three quarters of this half includes quarrels and fighting for power between brothers, uncle and cousin, between cousins within the same family orbetween two different Emirates attempting to continue their dictatorship in Southern Kurdistan. Ottoman Empire was waiting their destruction on the borders when they were awaken, it happened exactly after 1835 when Ottoman commander Rasheed Pasha attacked Botan, Soran and Badinan Emirates in 1836. Ottoman Empire could dissolve and end the power of both Emirates of Soran and Badinan in six years. Ottoman power returning to the central lands of northern Kurdistan andinterests of countries such Britain, France, Russia and Germany played an important role in ending Kurdish Emirates in Southern Kurdistan. Thus, continual agreements between Ottoman and Qajaryempires especially the last one which was Erzurum Agreement in 1847 resulted into the process of Renaissance delayed national thought in South Kurdistan in the first half of the $19^{\text {th }}$ century.
\end{abstract}

Keywords: national thought, Kurd, Emirates, Mir, Southern of Kurdistan

\section{Recommended citation:}

Galalaye, M. A. I. (2016). The impact of the power struggle in the Renaissance delayed national thought in South Kurdistan 1800-1850. International Journal of Kurdish Studies 2 (3), 196 - 208.

\footnotetext{
${ }^{1}$. Assistant Lecture, History Department, Faculty of Arts, Soran University, Iraq Kurdistan Rgion, Erbil-Soran, for further information contact, mohammed.ibrahim@soran.edu.iq
} 


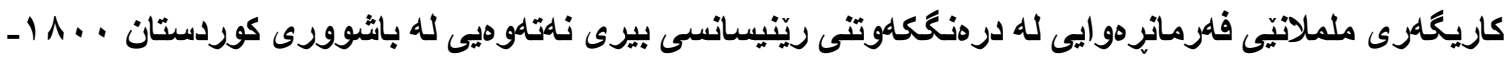
$1 \wedge 0$.

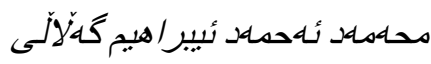

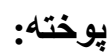

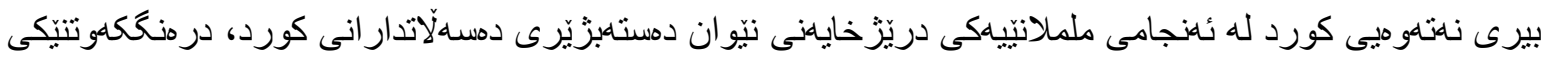

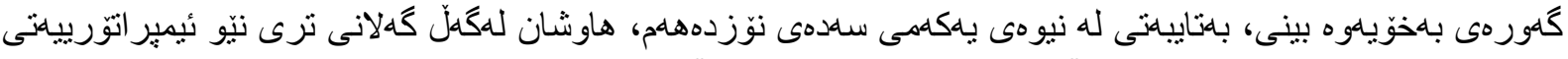

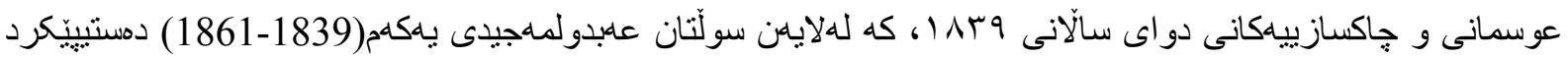

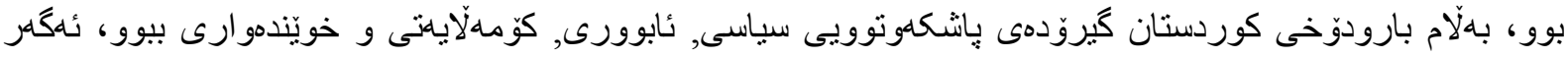

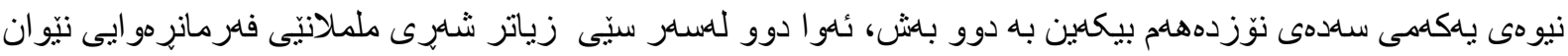

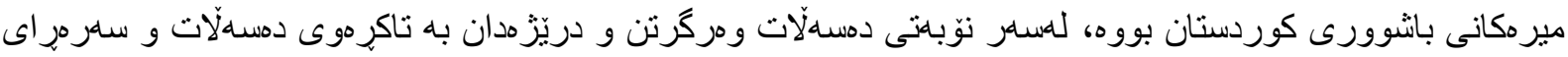

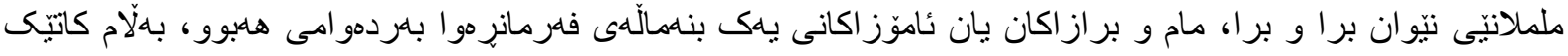

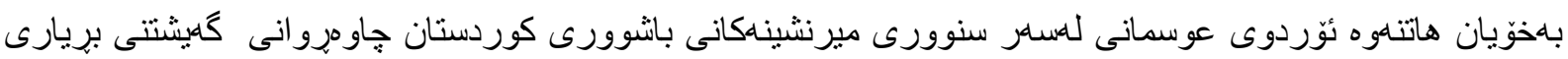

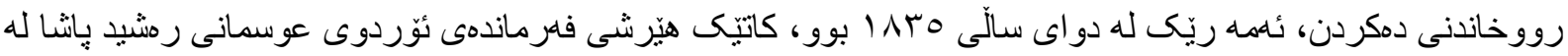

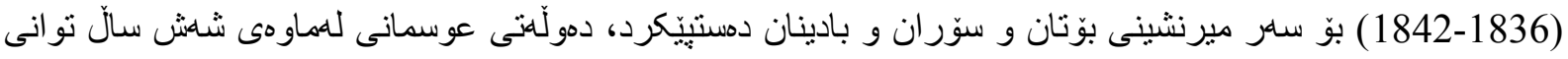

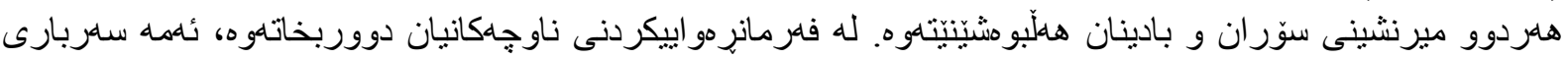

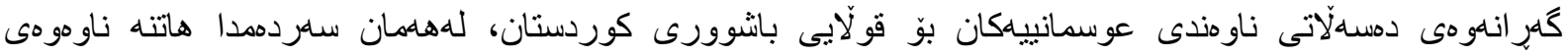

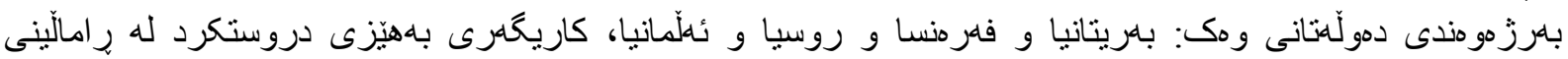

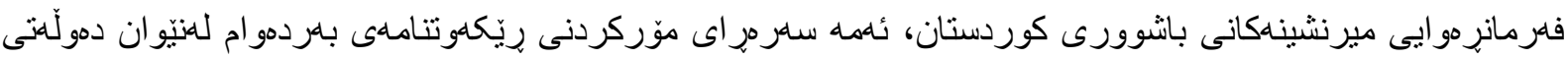

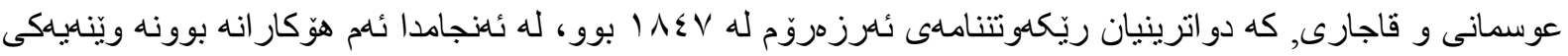

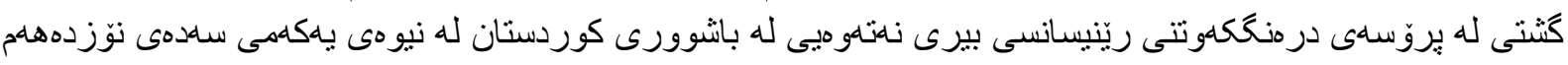

كليله وشـكان: بيرى نهتهو ديى، كورد، ميرنشينهكان، مير ، باشوورى كوردستان. 


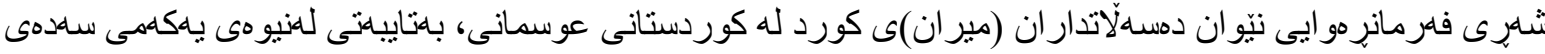

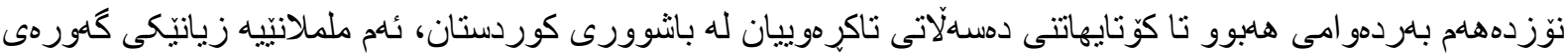

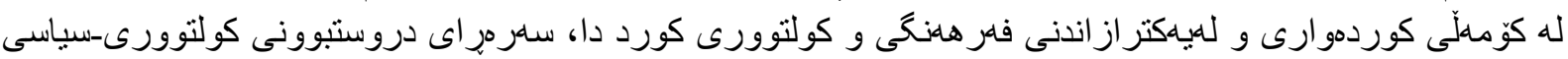

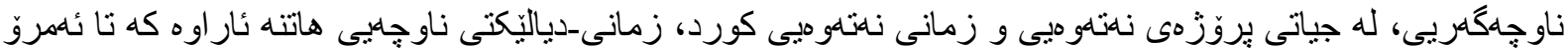

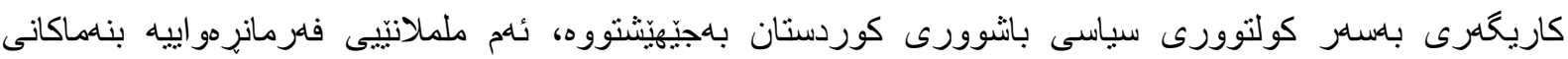

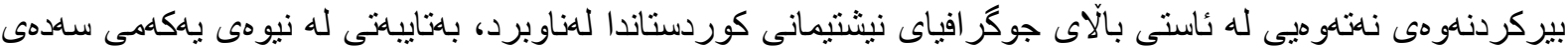

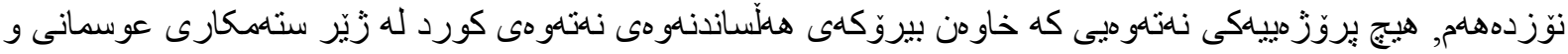

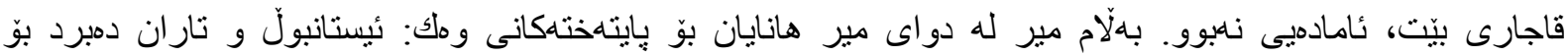

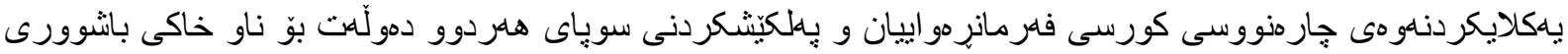

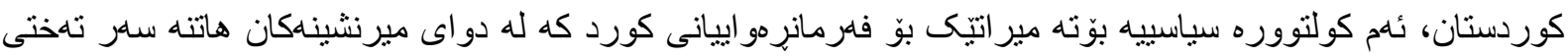

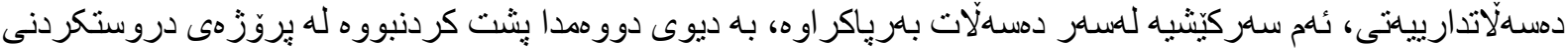

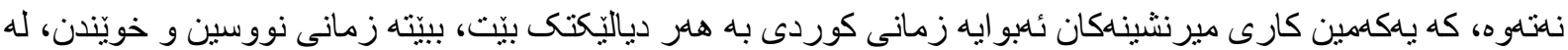

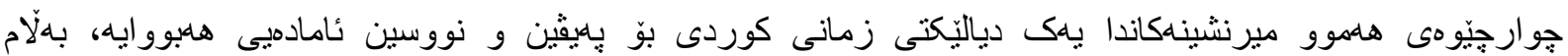

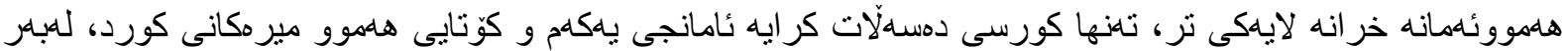

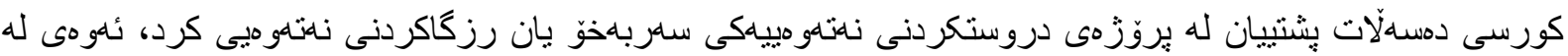

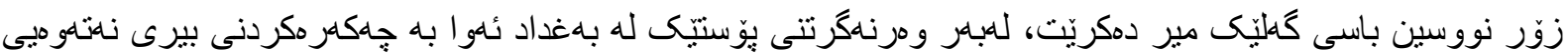

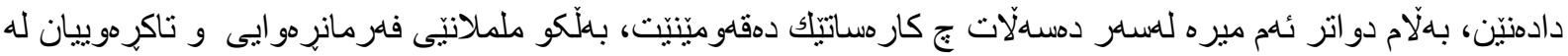

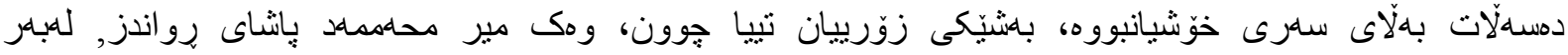

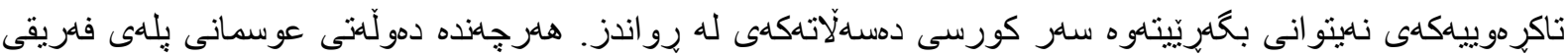

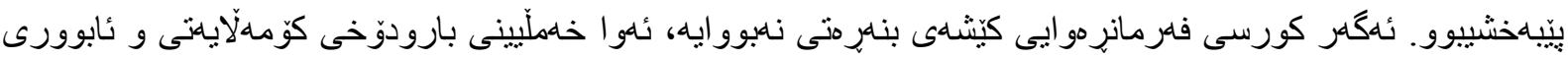

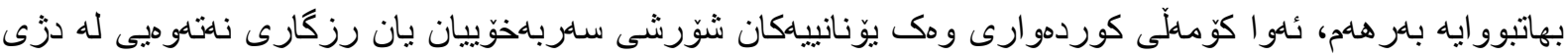

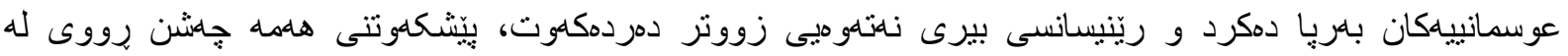

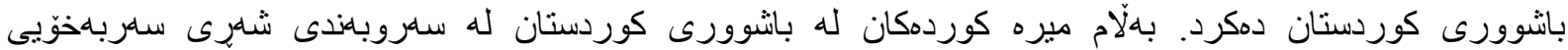

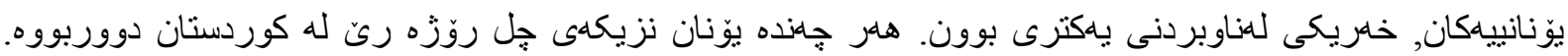

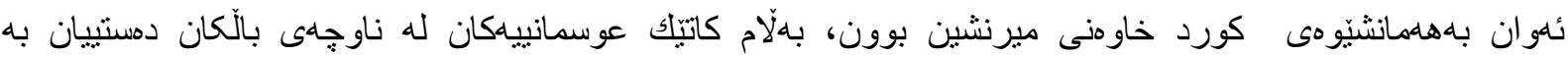

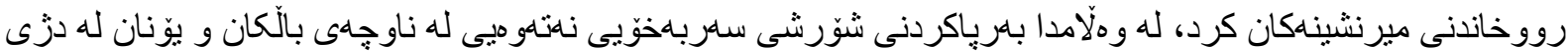

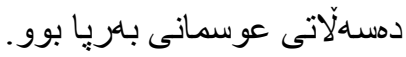

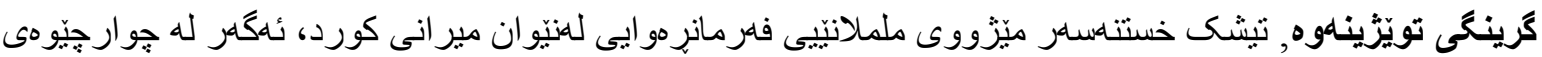

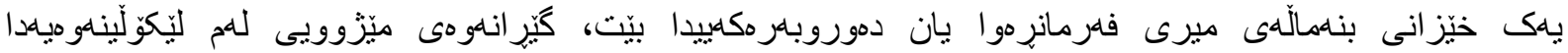

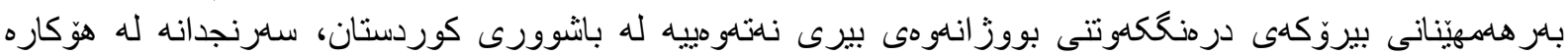
ميّزوزوييهكان.

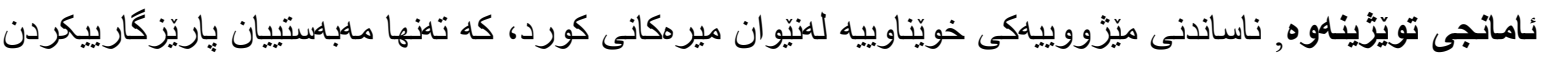

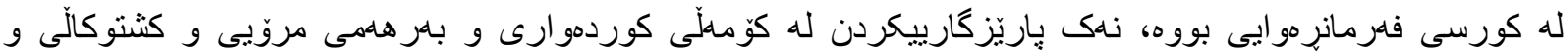

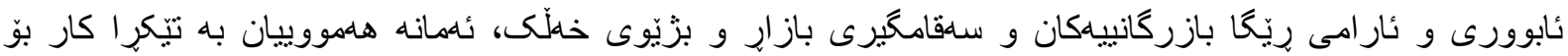

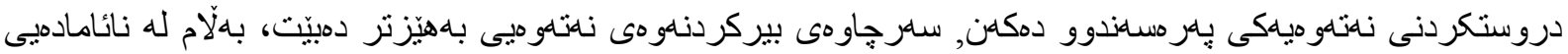

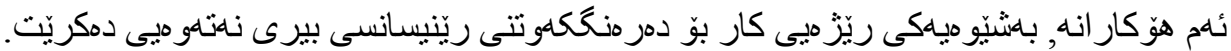

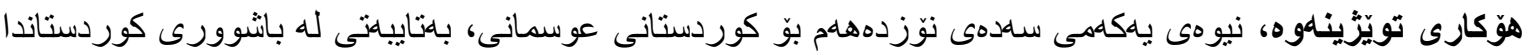

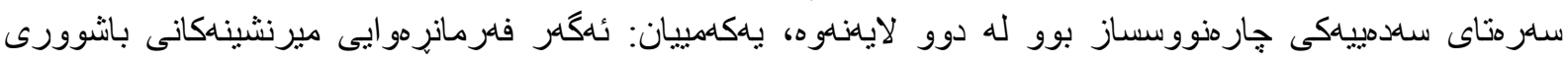

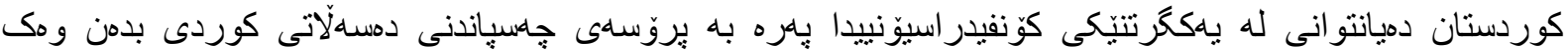

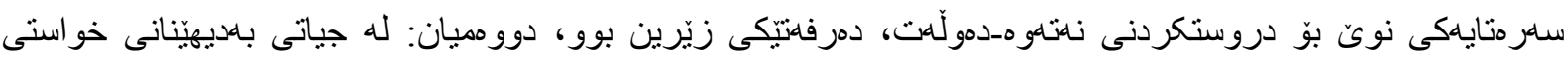




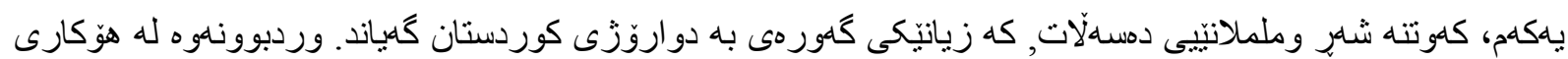

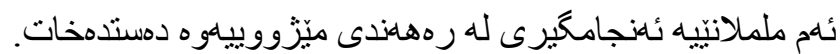

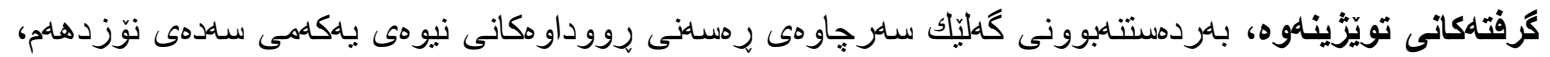

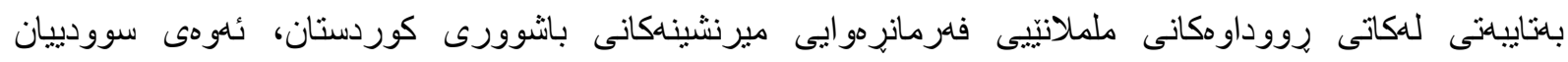

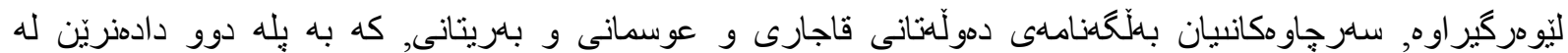

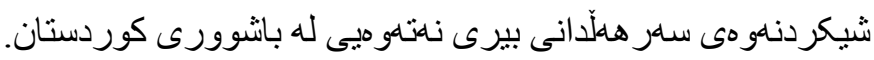

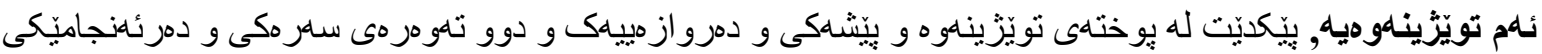

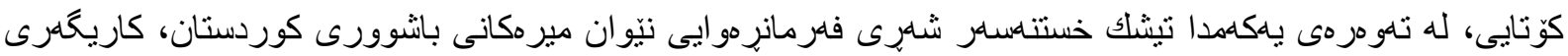

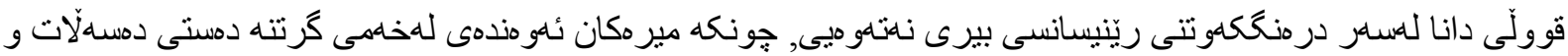

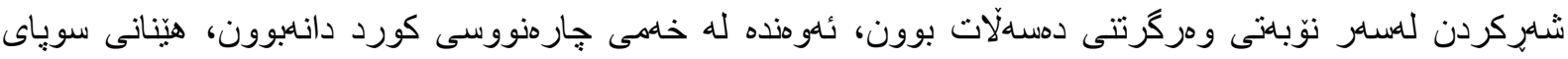

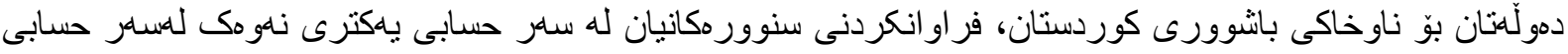

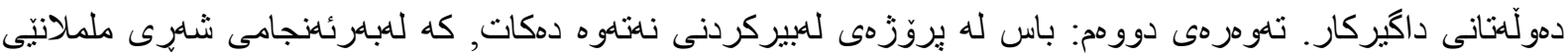

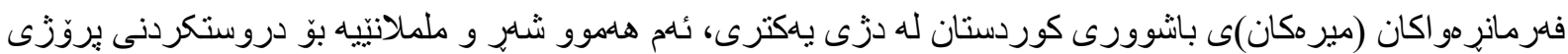

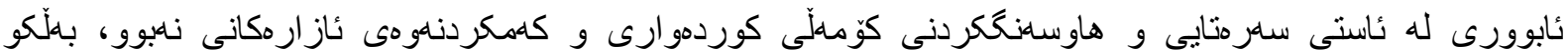

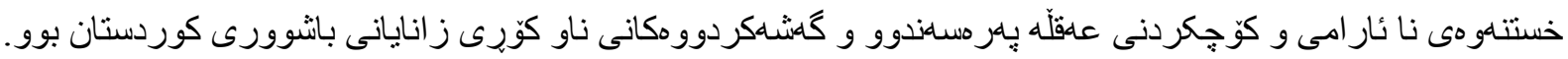

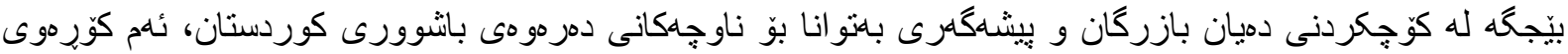

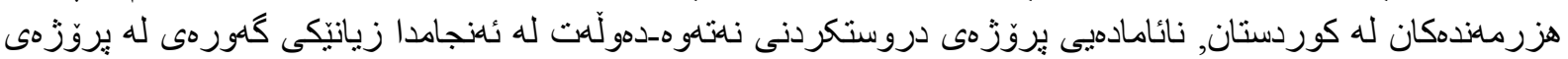

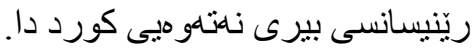

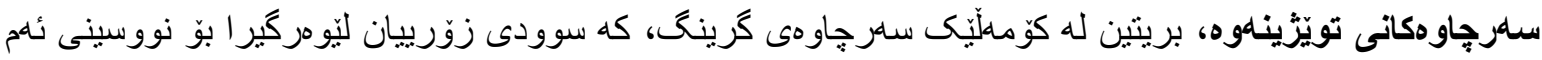

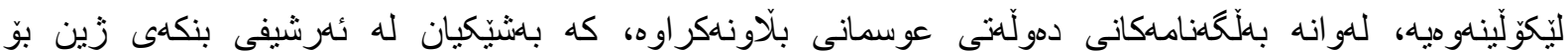

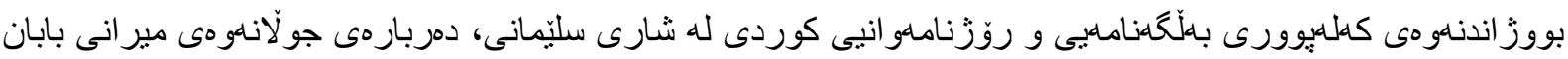

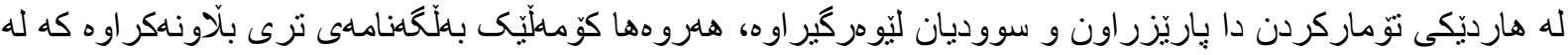

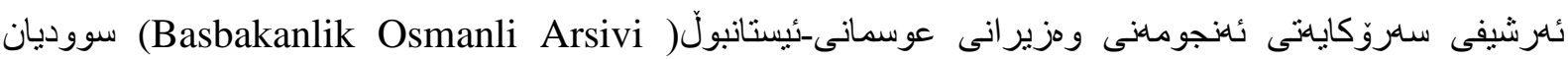

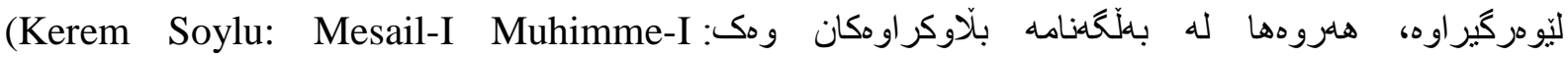
Kurdistan(Kurdistanin Onemili Meseleleri Osmanlica ve Turkce)

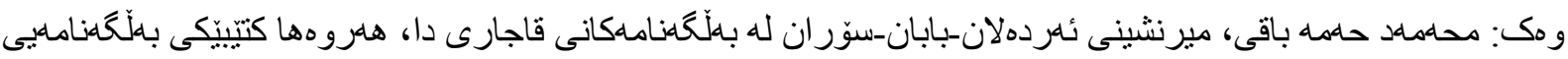
به زمانى ئينكليزى، وةك:-1831 (A.B. Cunningham: The Early Correspondence of Richard Wood

دهروازه:

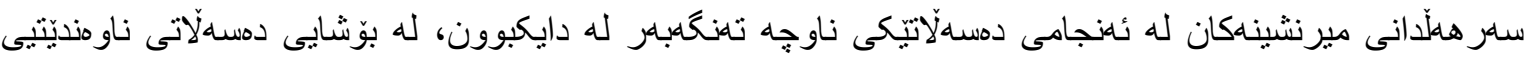

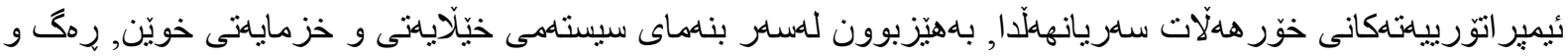

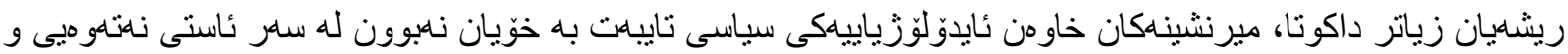

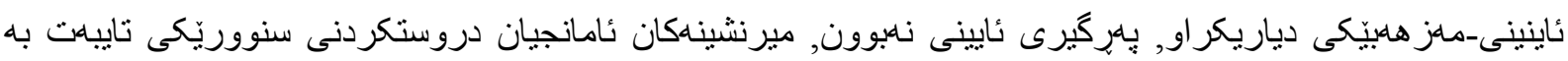

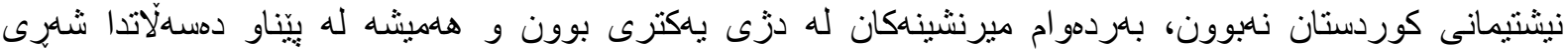

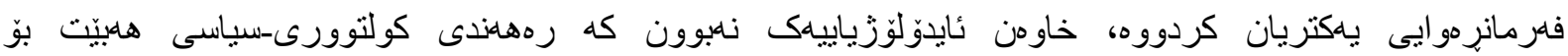

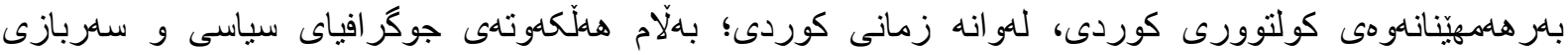

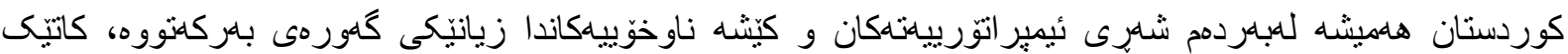

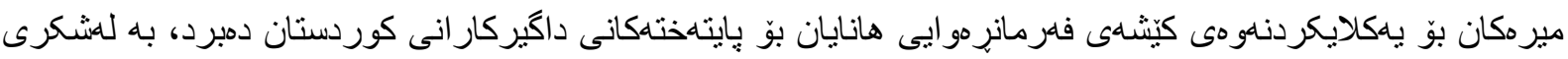

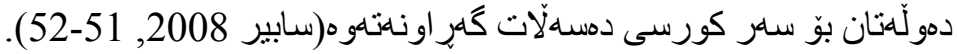




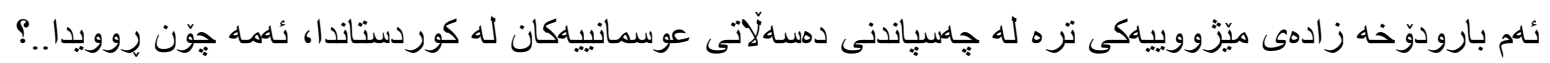

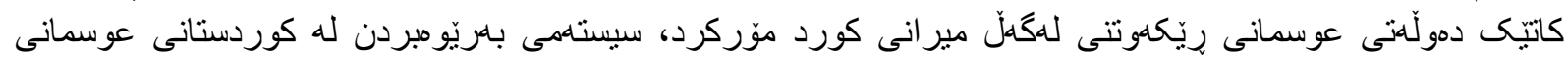

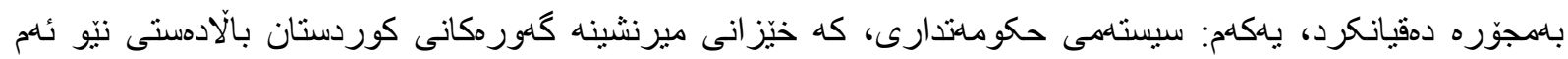

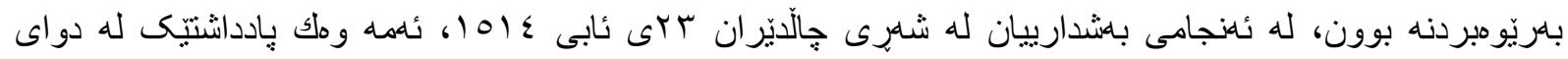

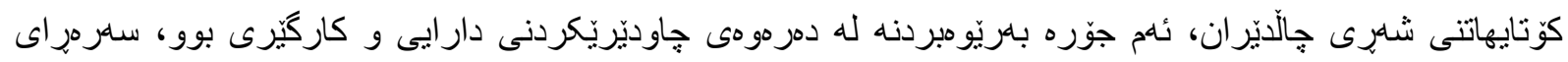

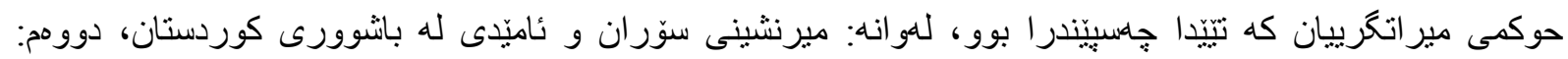

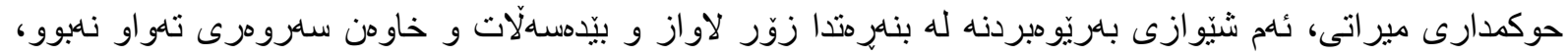

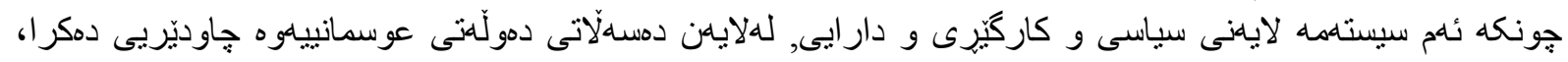

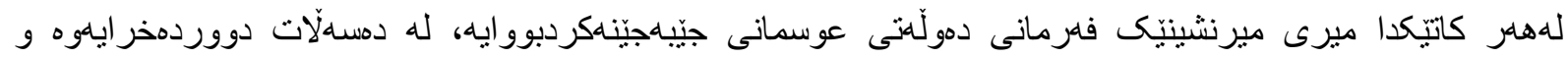

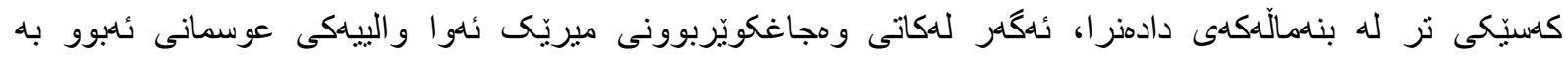

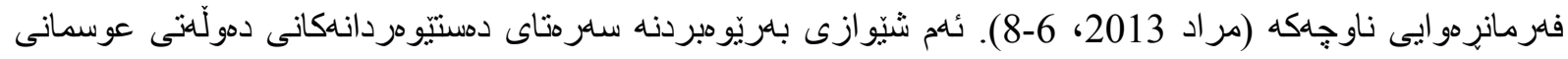

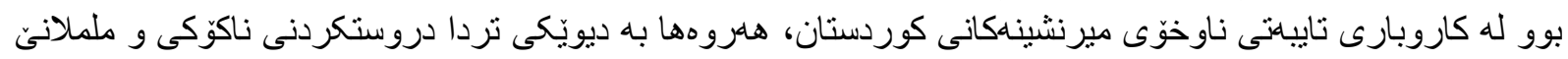

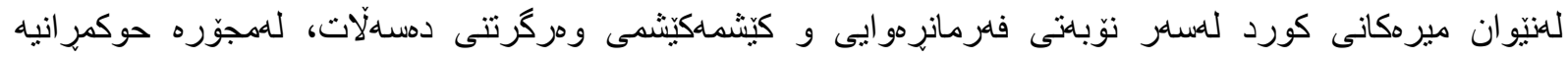

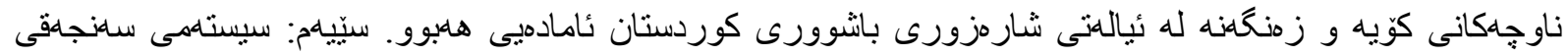

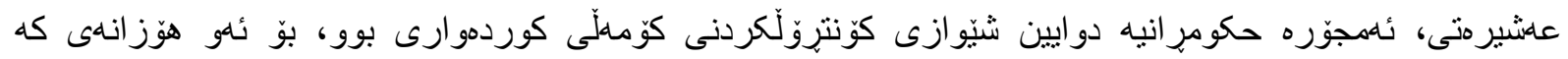

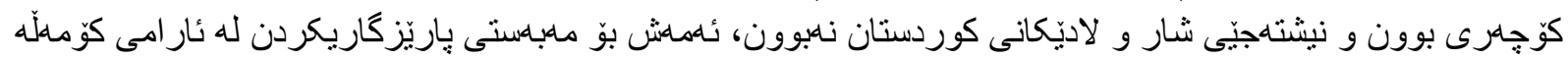

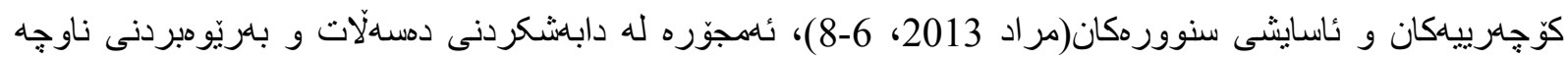

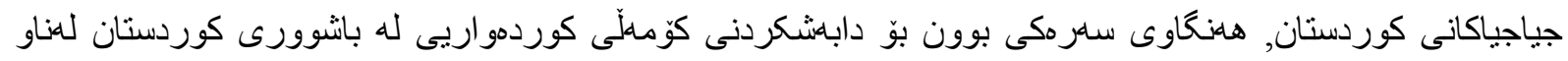

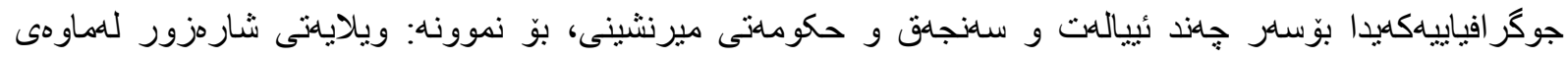

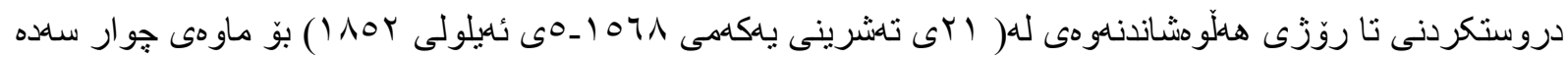

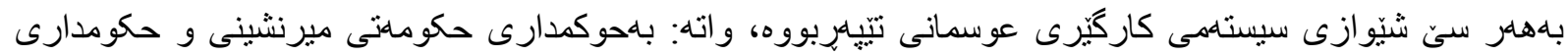

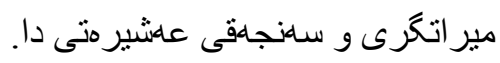

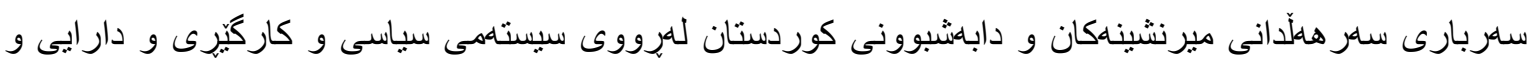

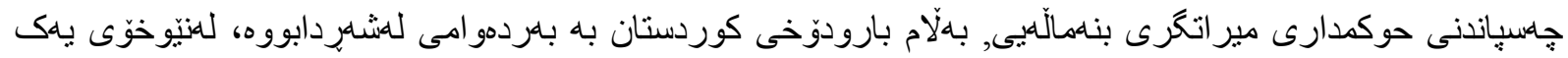

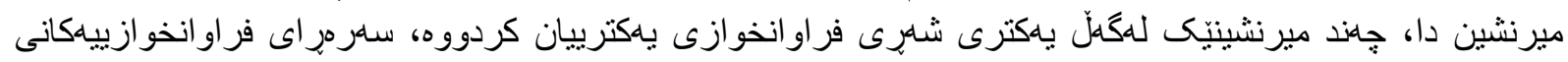

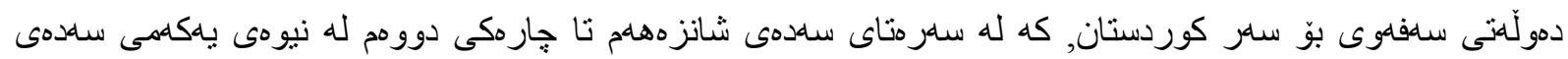

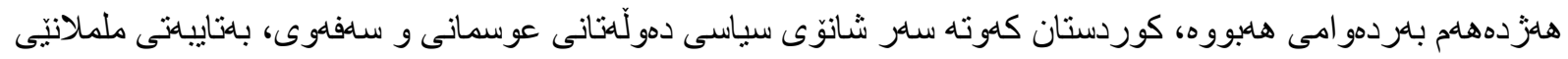

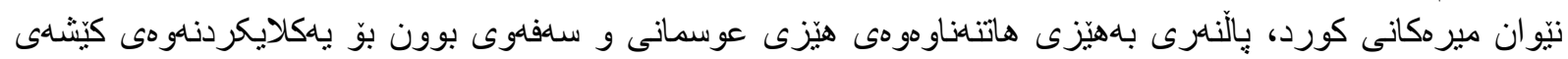

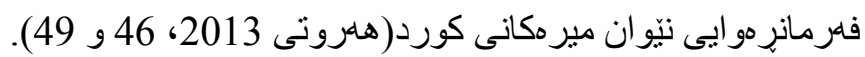

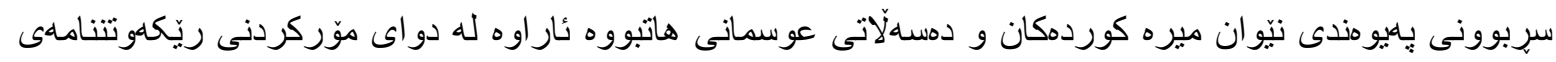

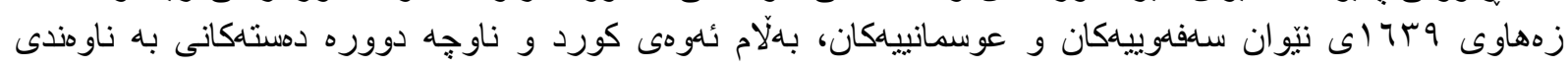

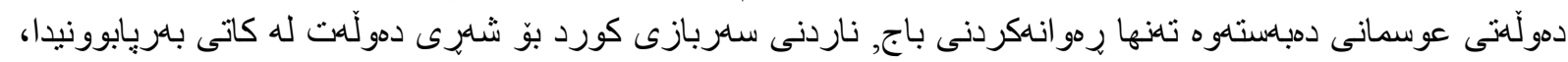

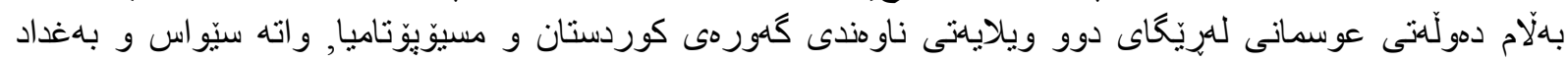

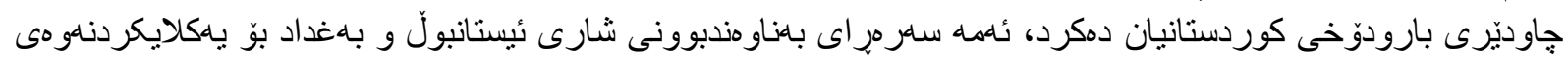

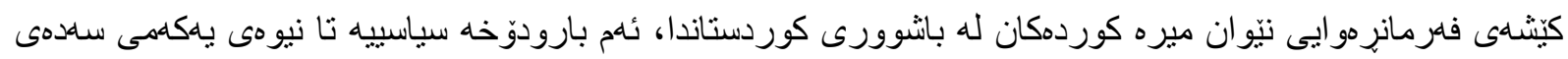

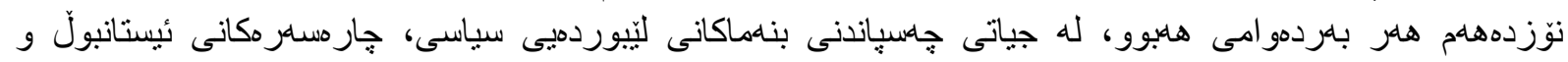

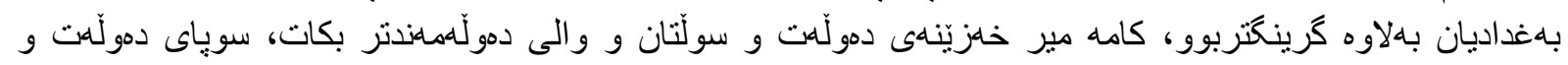

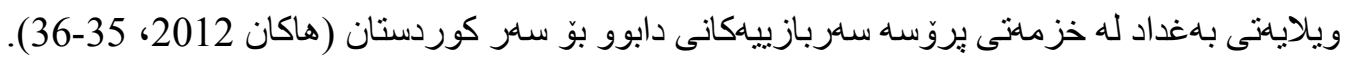

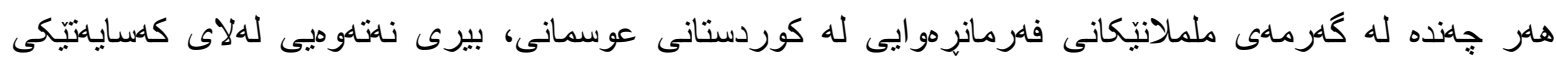

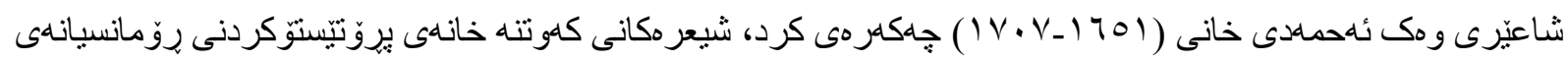

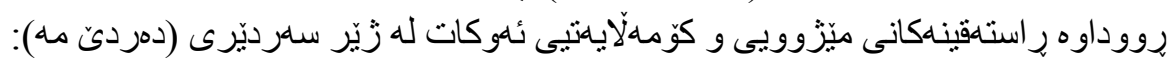




\section{ئايا ب ت ومجهي مانه مهحروم \\ بيلجو مله زَ بوّ جهى مانه مهحكوم}

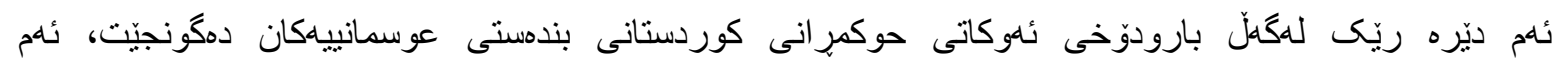

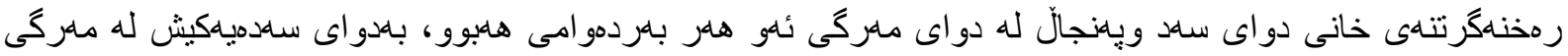

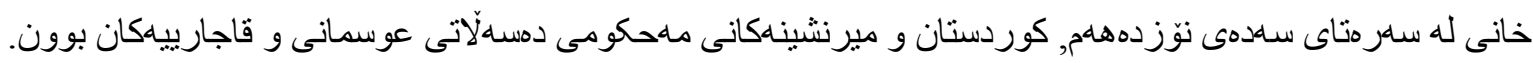

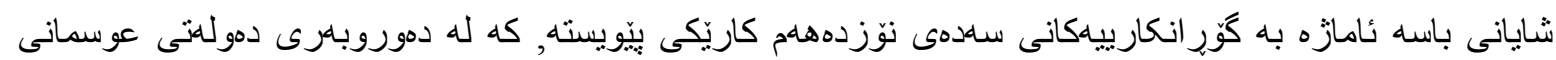

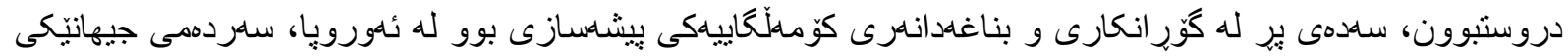

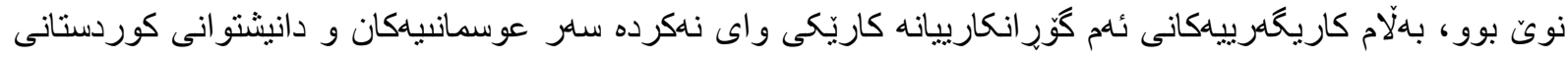

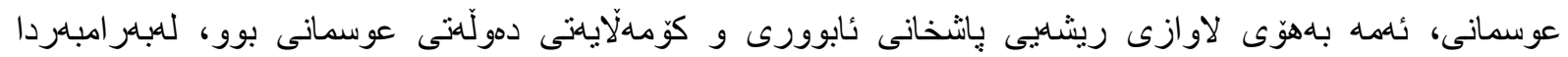

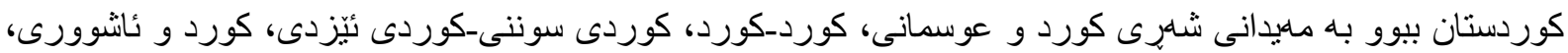

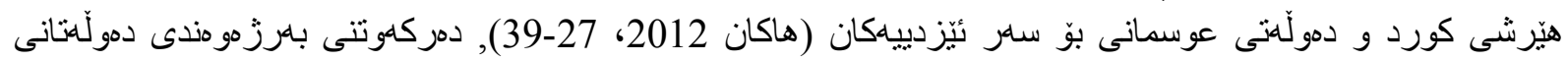

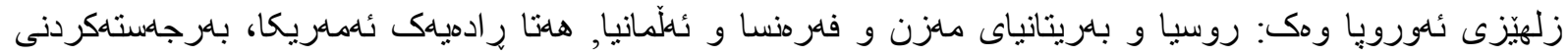

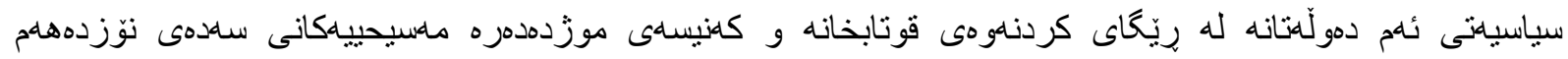

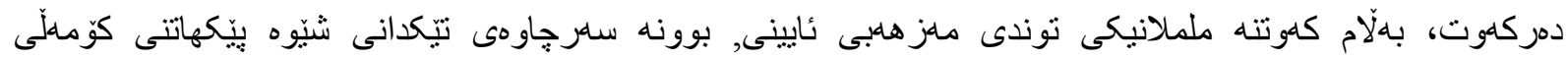

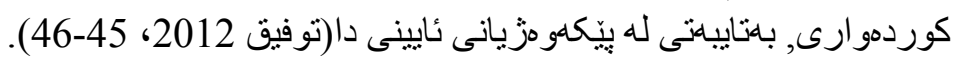

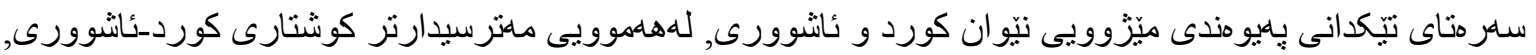

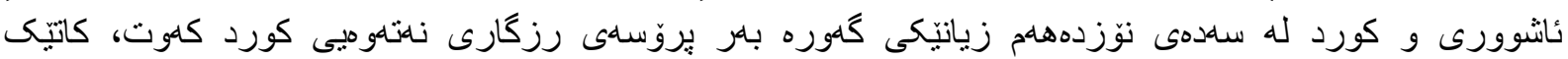

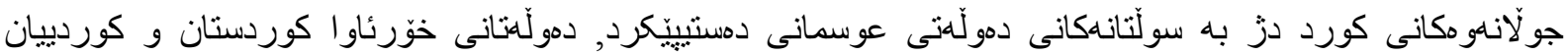

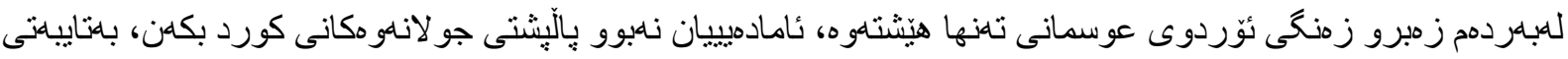

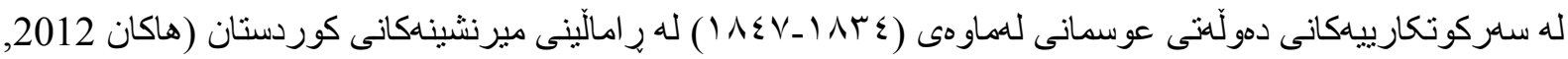

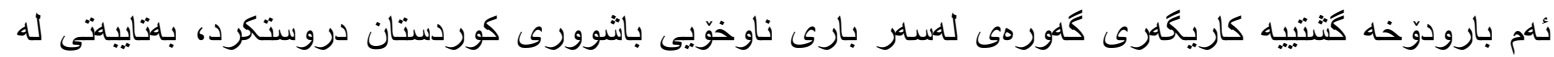

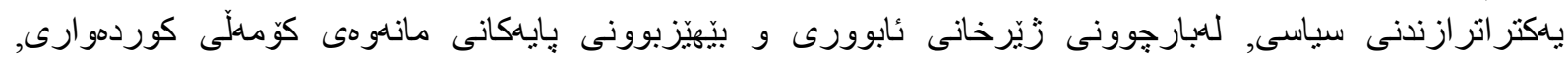

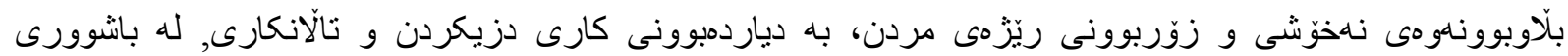

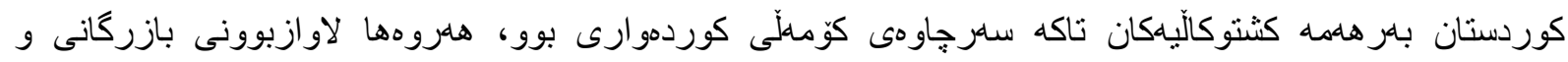

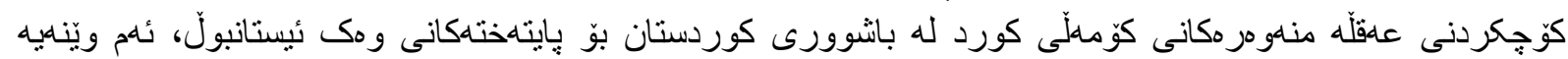

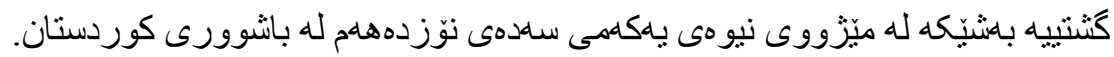

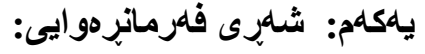

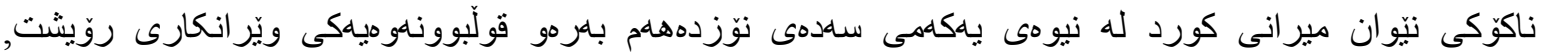

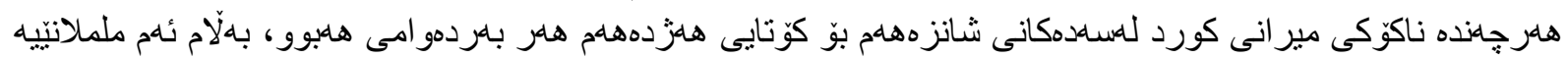

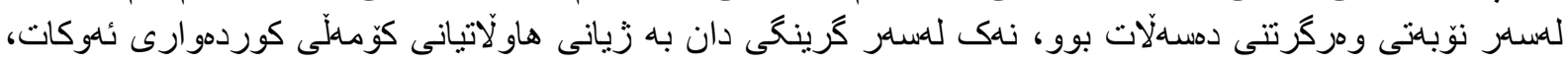

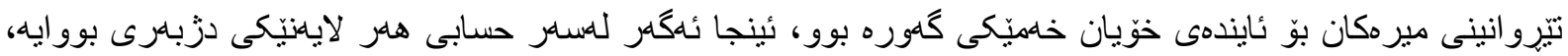

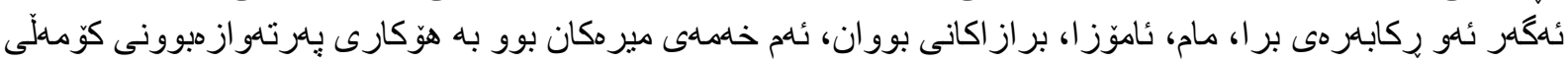

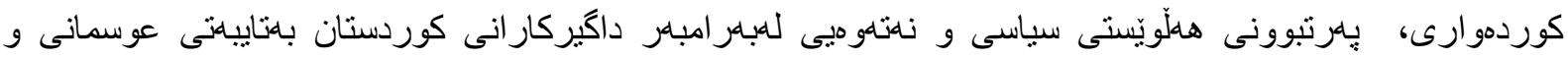

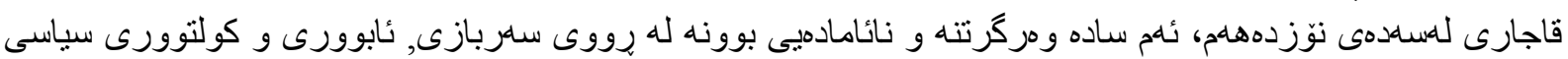

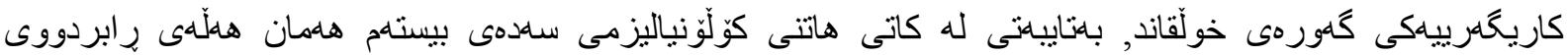

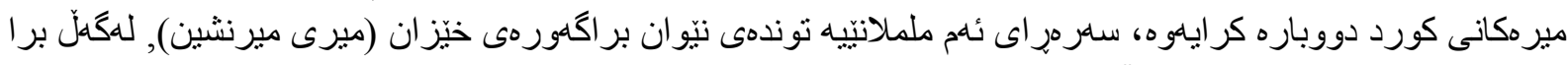

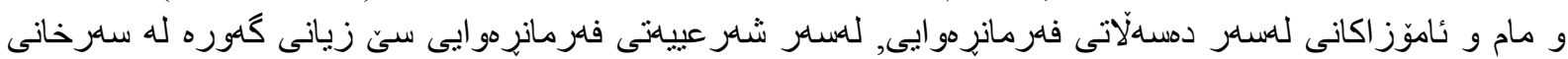

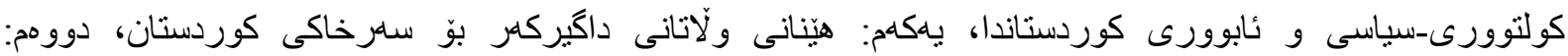




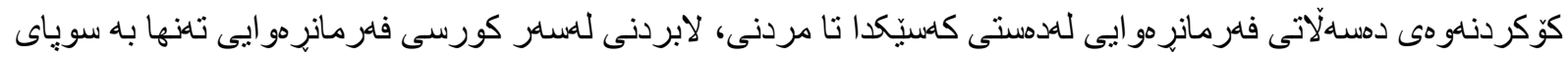

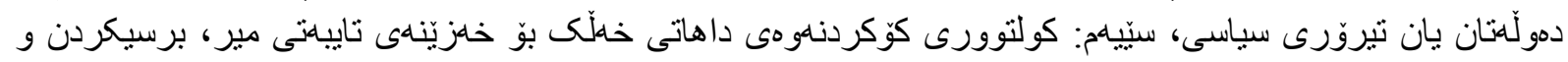

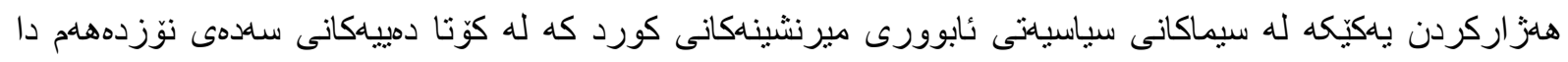

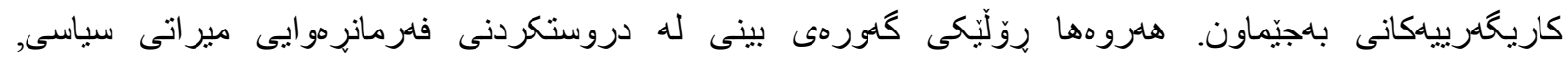

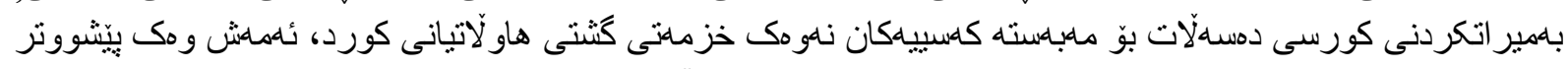

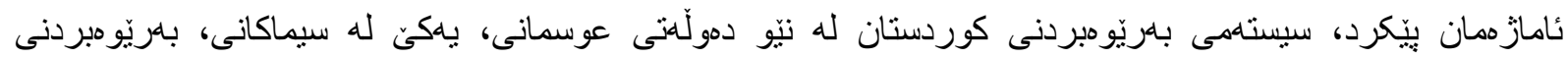

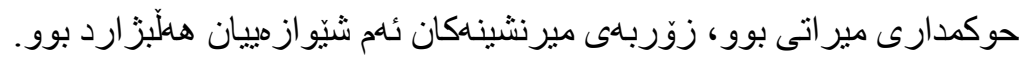

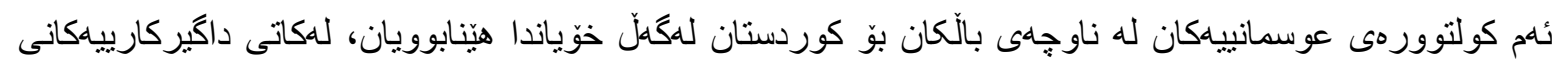

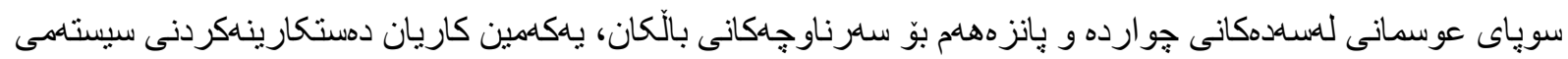

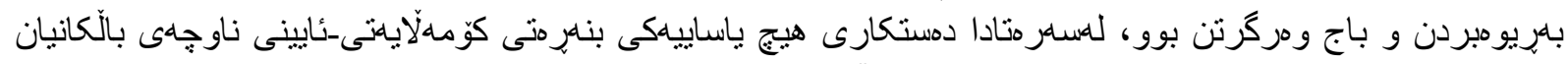

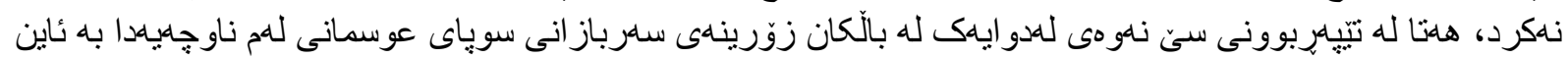

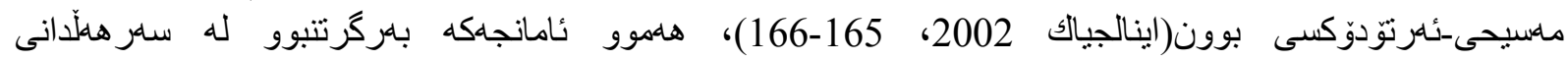

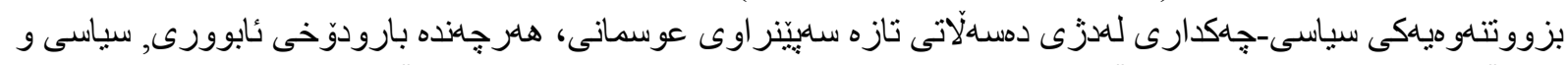

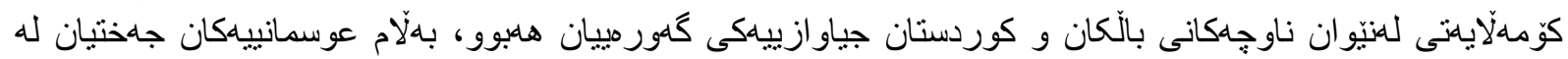

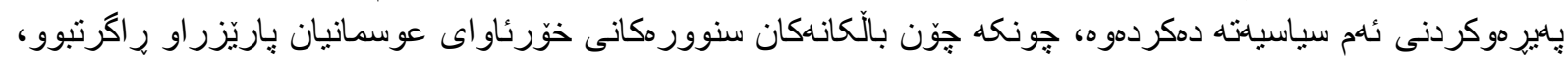

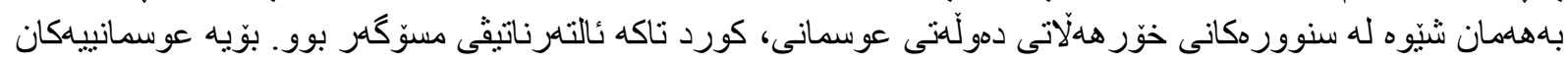

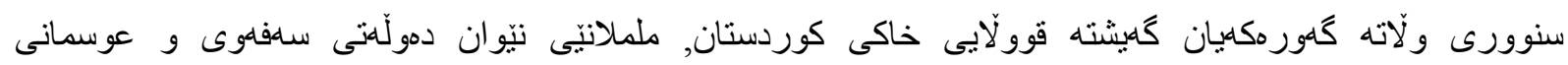

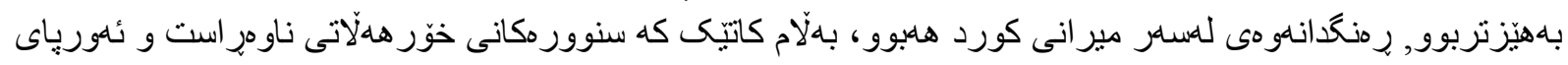

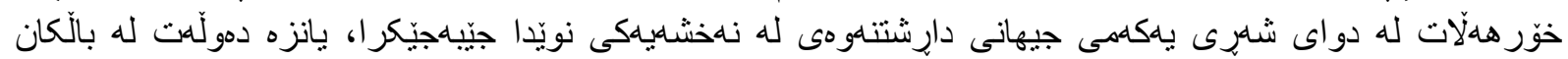

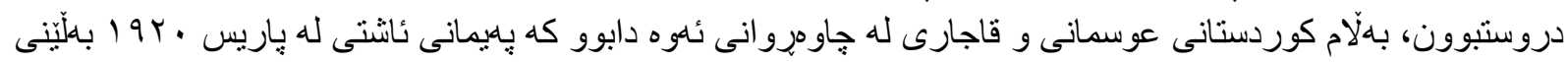

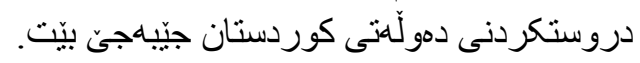

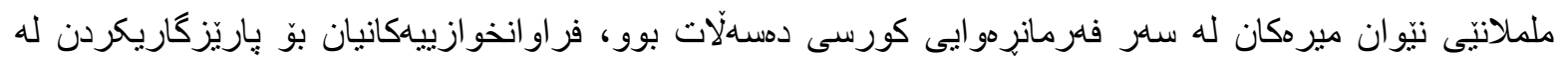

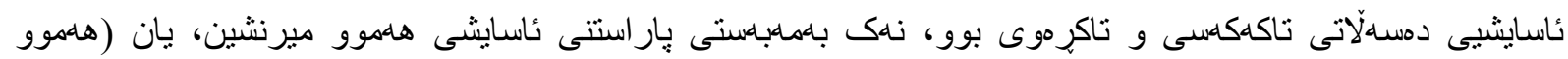

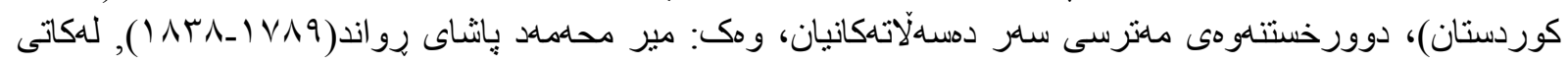

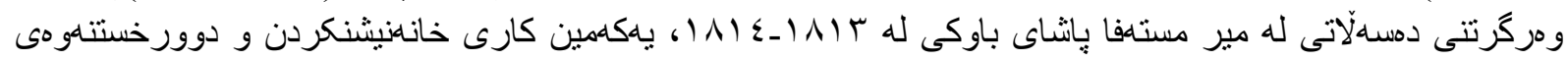

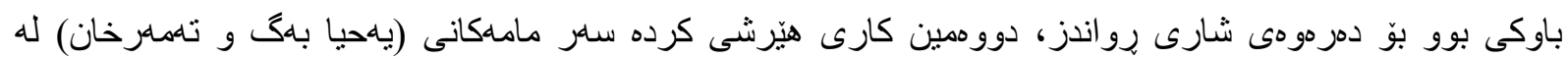

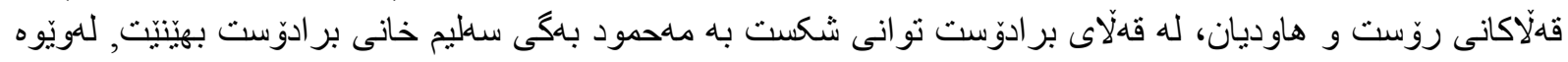

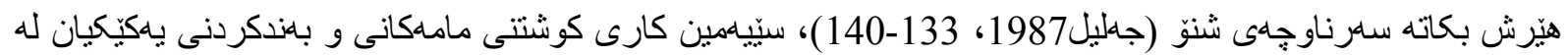

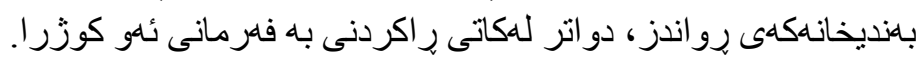

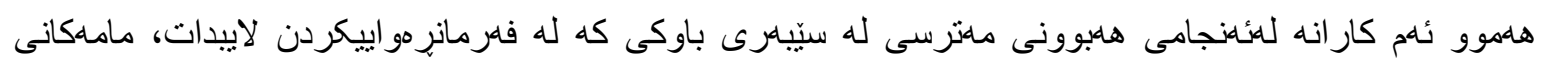

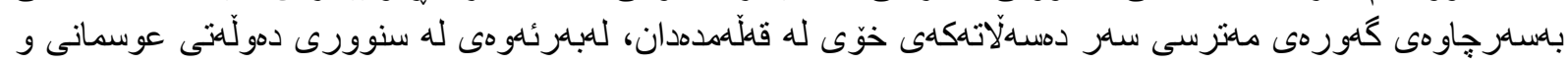

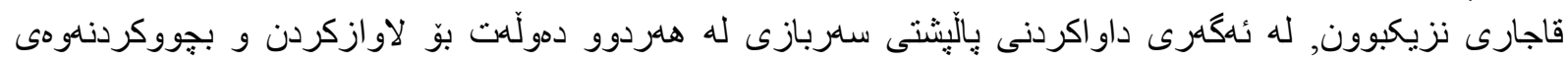

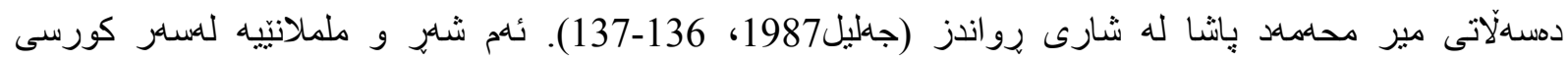

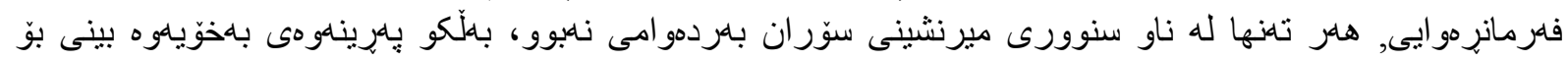

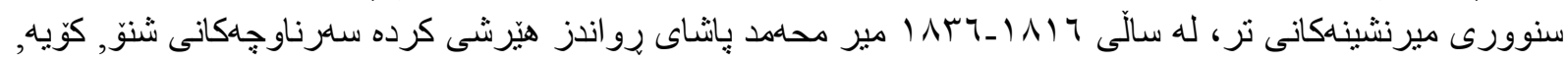

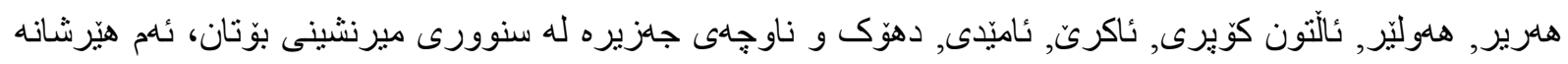

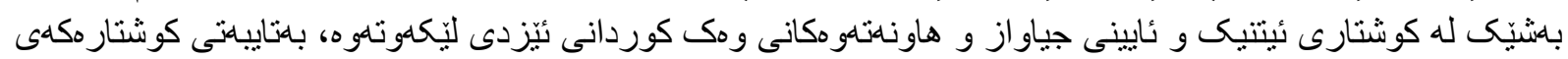

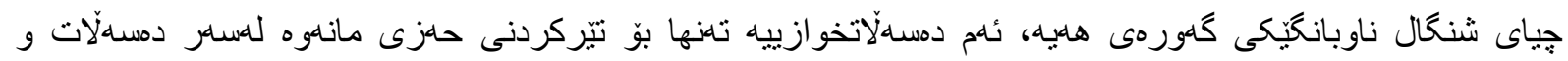

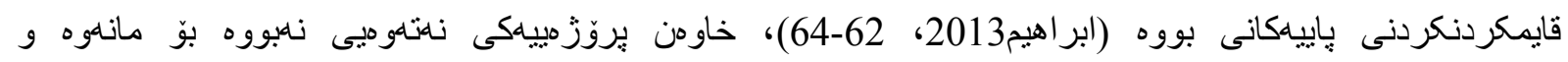

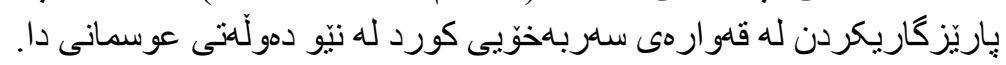




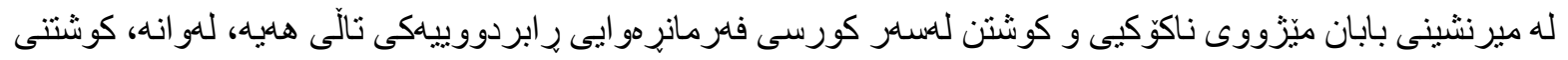

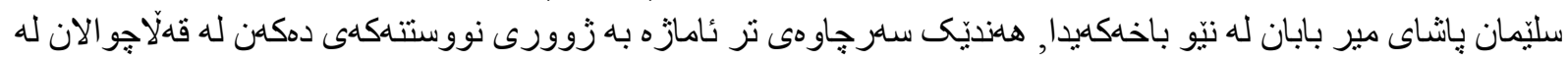

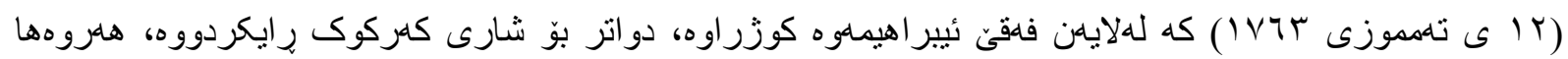

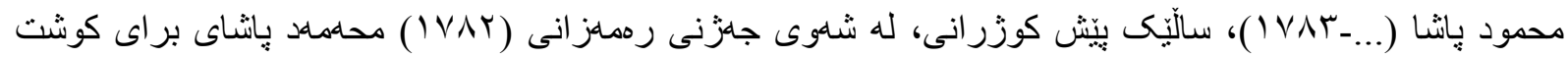

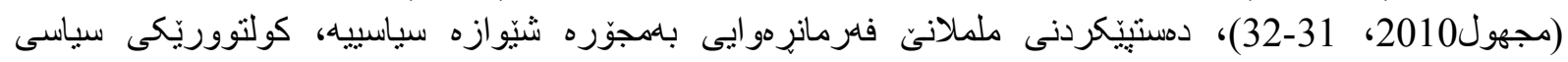

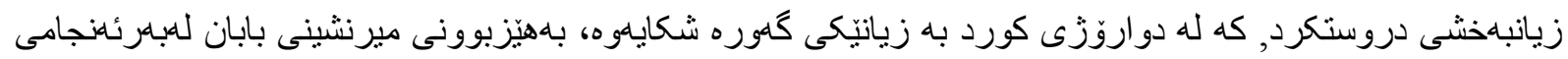

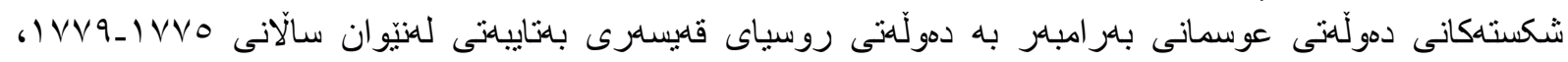

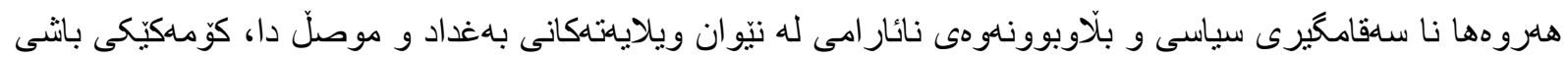

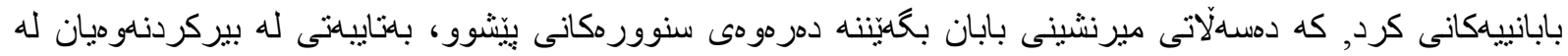

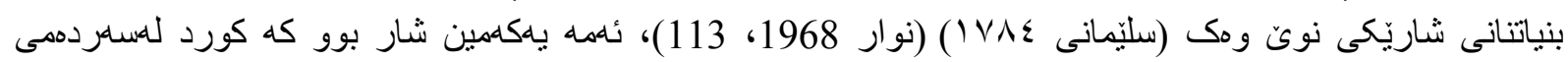

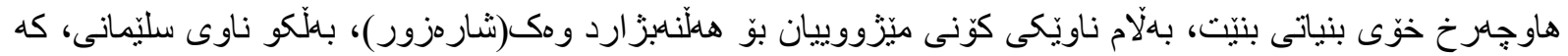

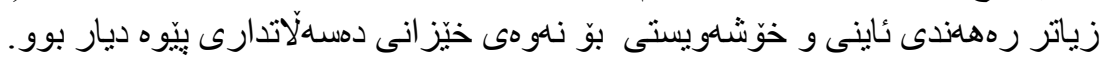

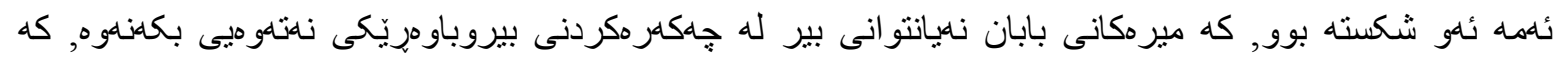

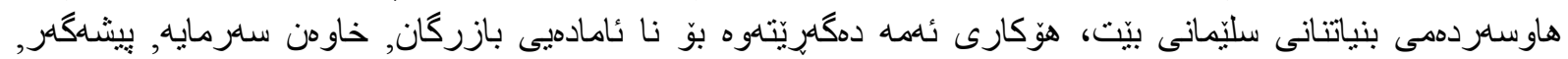

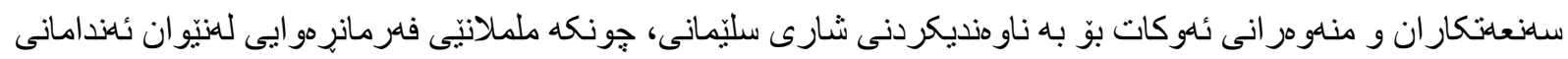

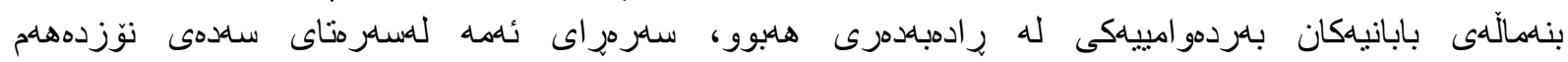

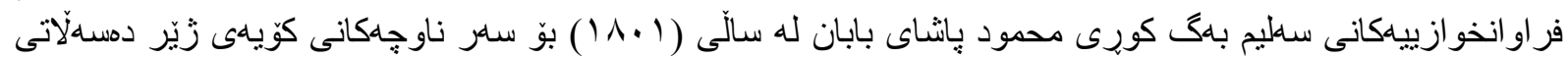

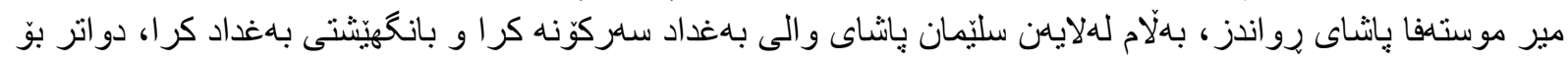

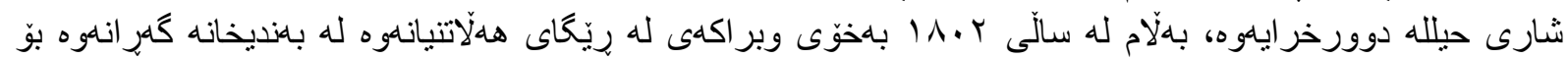

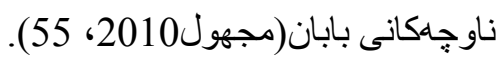

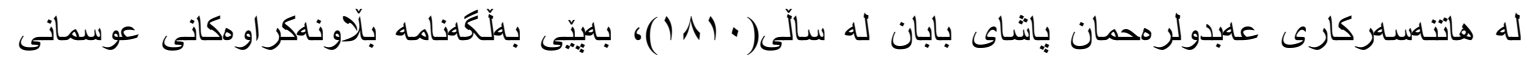

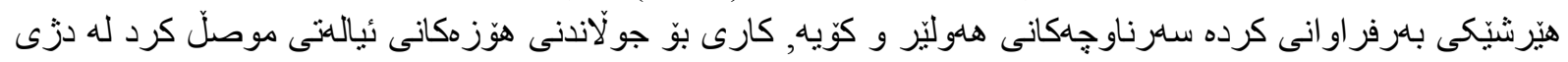

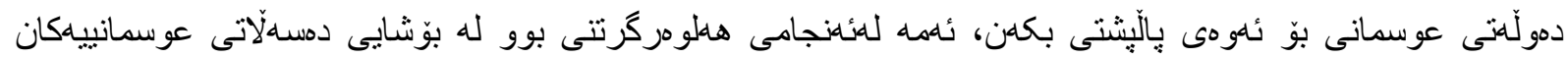
(B.O.A:HAT:0397/20899-D)

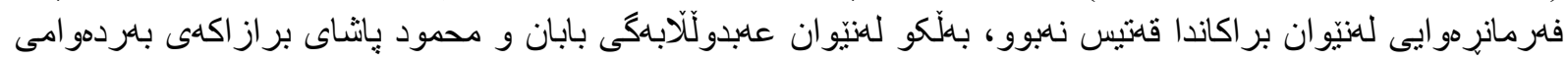

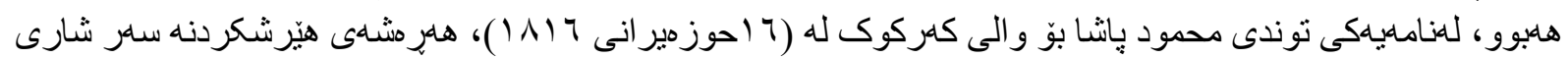

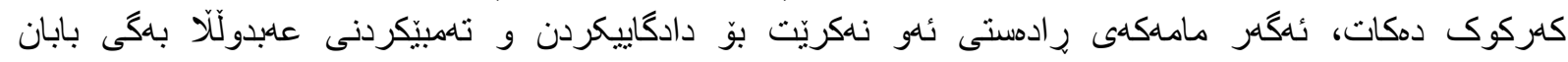

(باقى 2003،

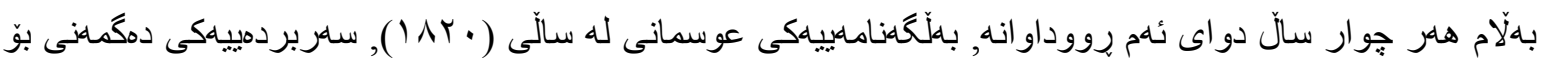

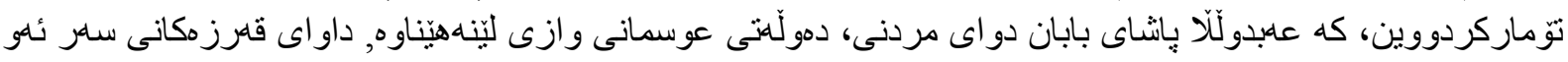

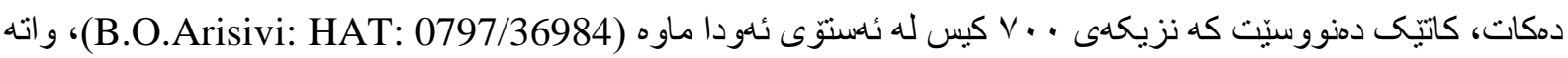

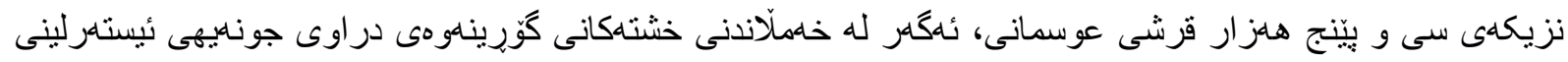

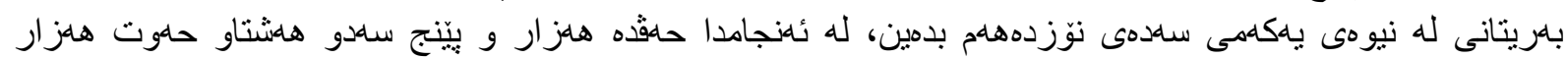

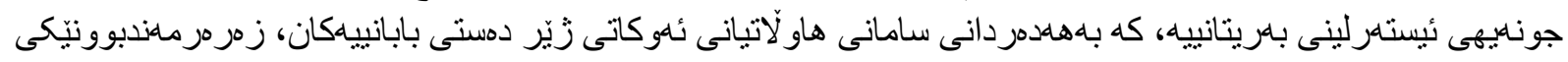

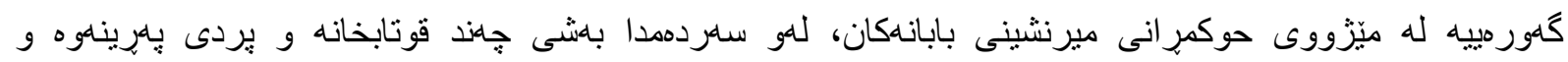

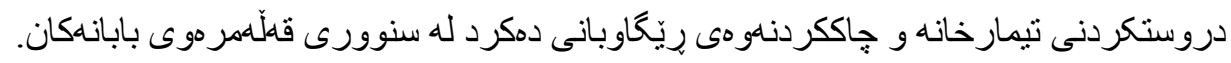

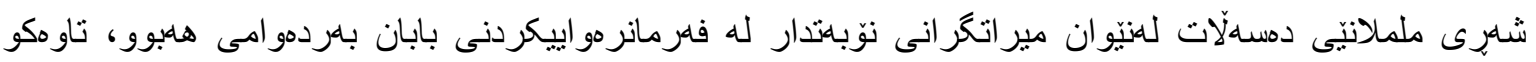

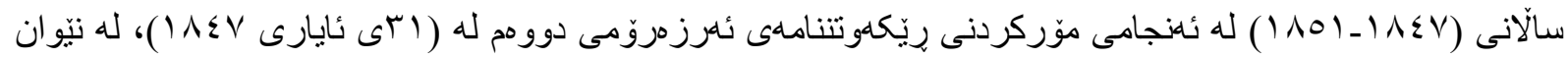

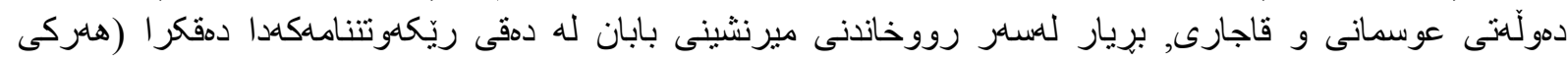

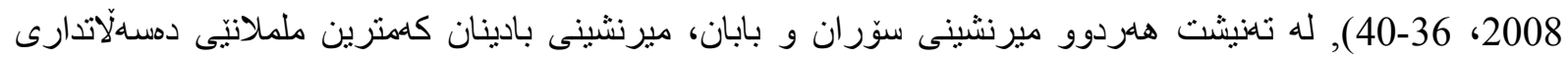

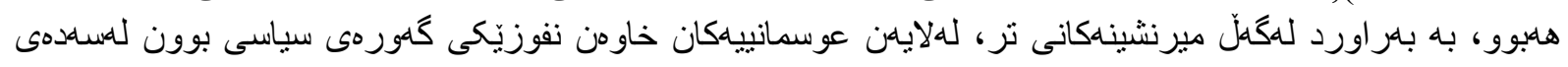




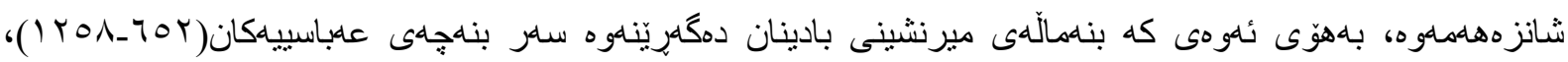

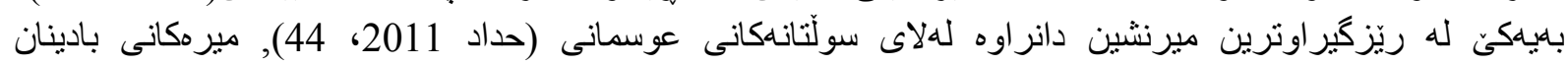

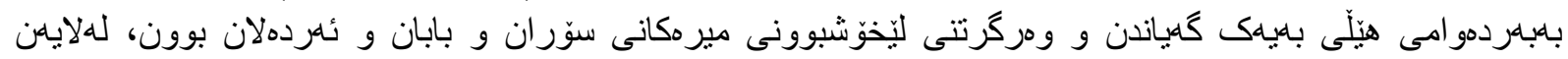

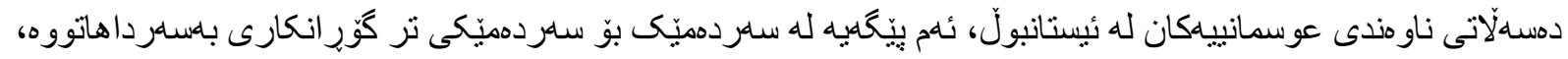

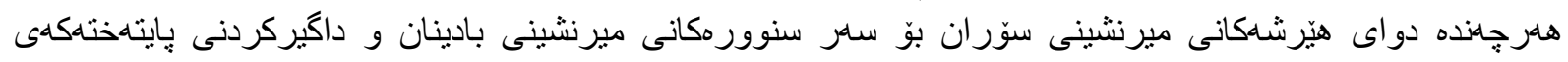

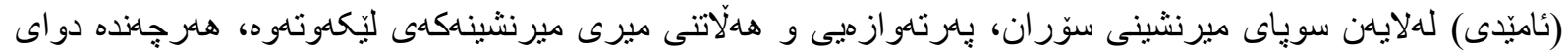

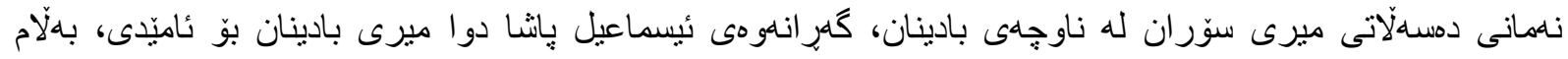

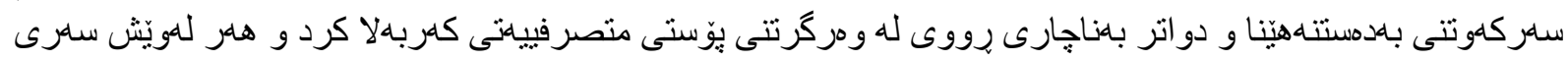

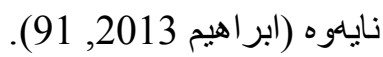

\section{دووهم: للهبيركردنى نـنهوه:}

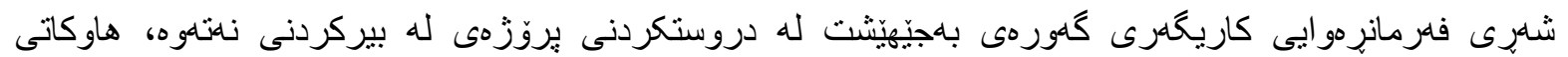

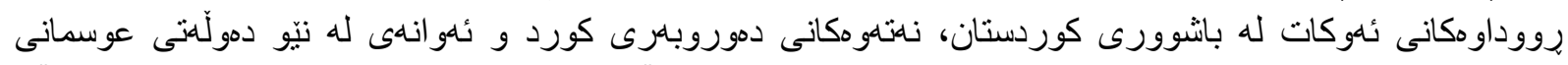

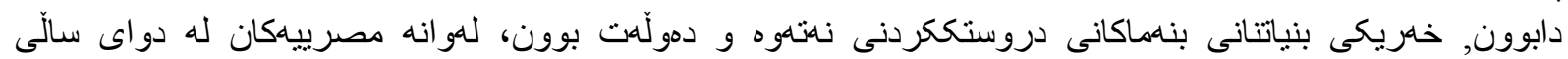

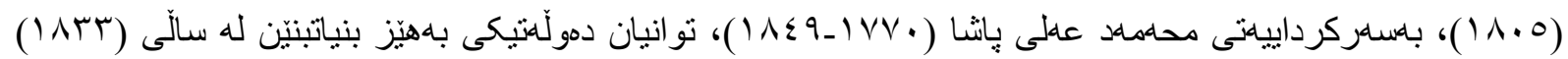

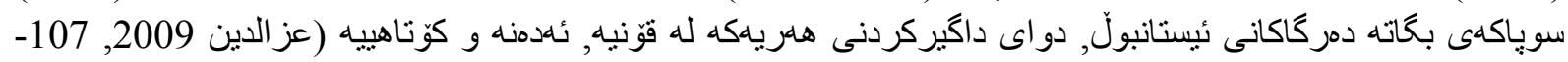

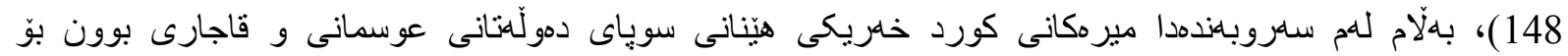

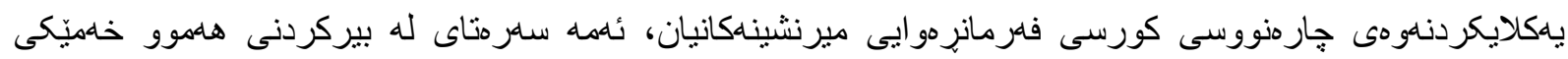

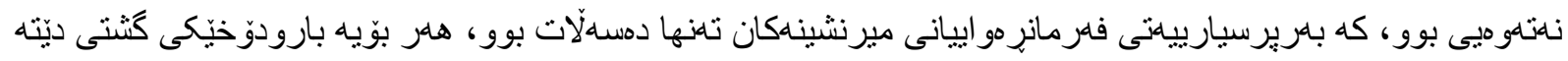

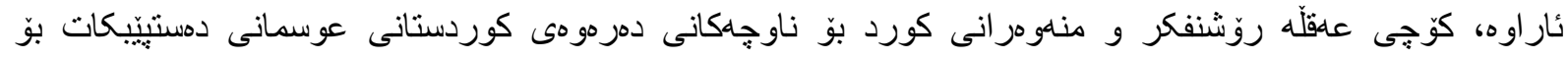

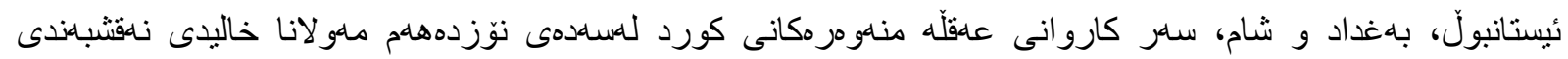

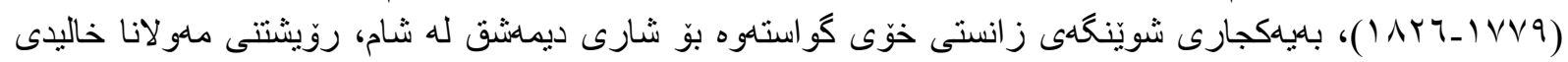

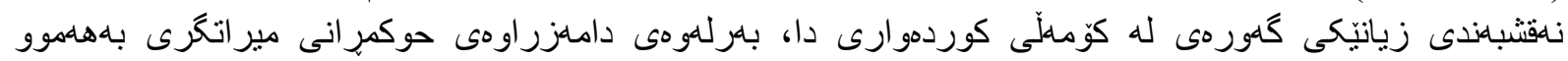

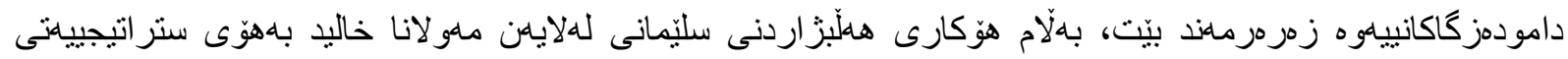

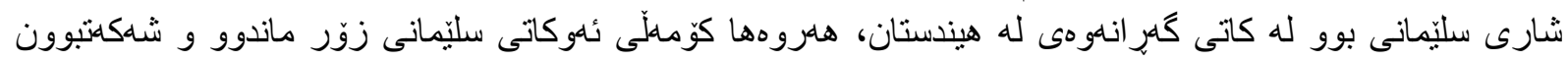

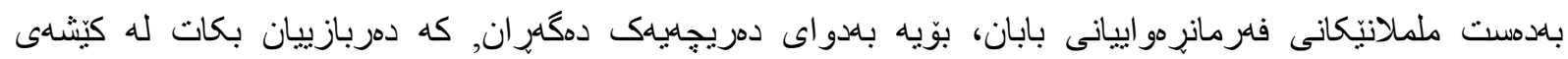

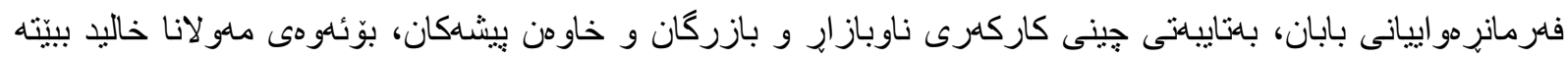

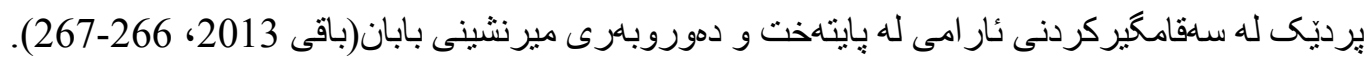

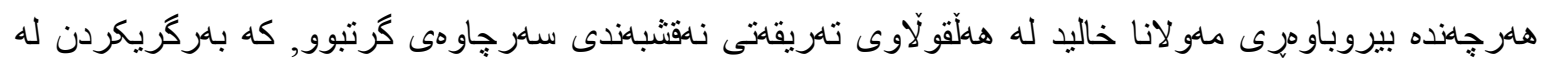

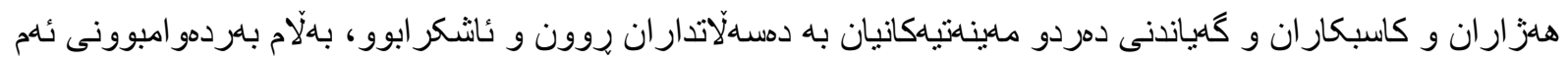

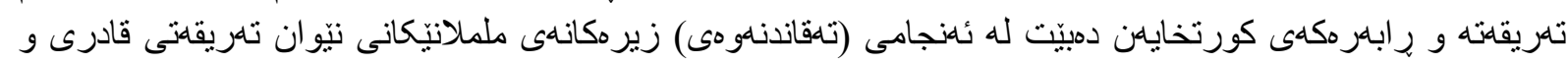

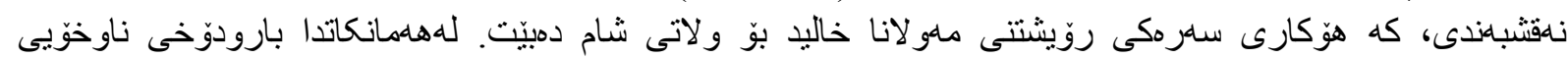

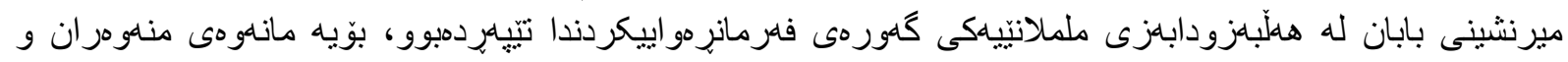

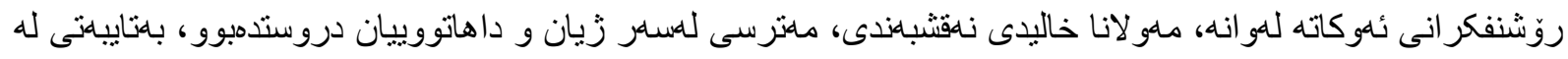

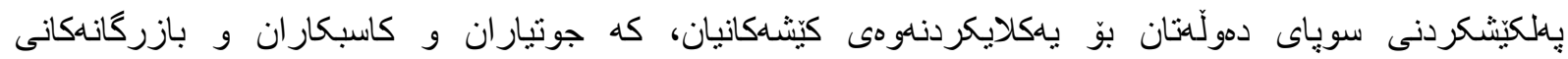

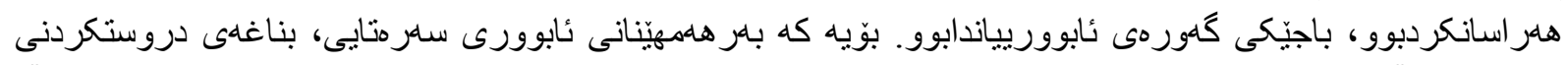

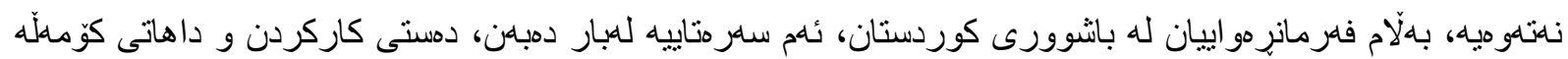

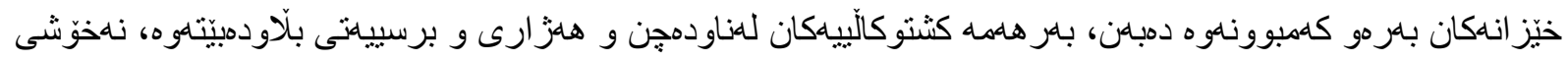

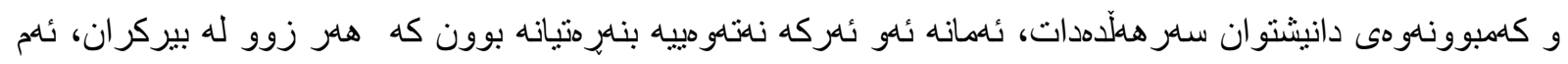

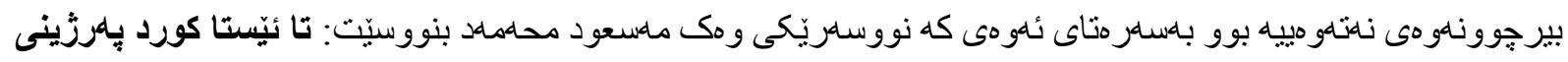




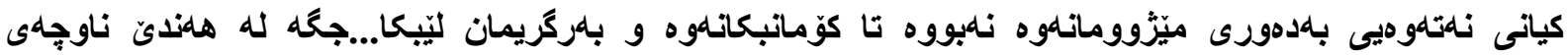

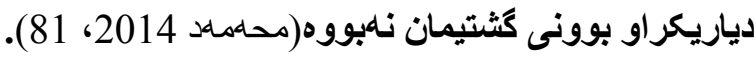

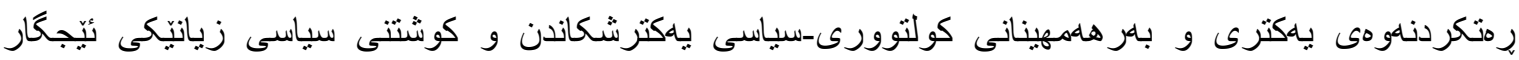

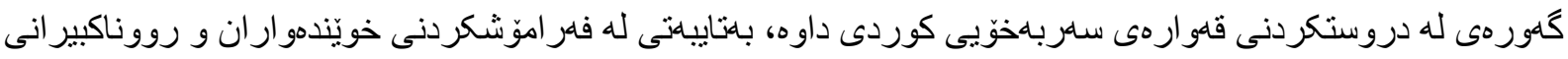

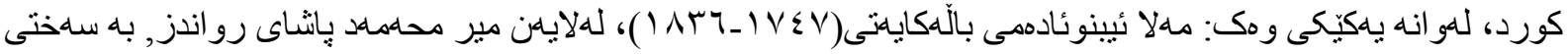

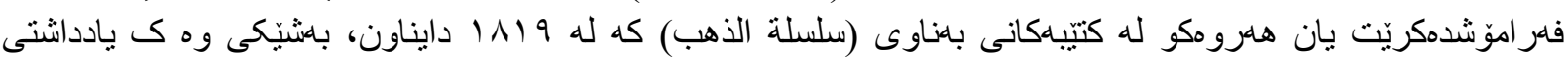

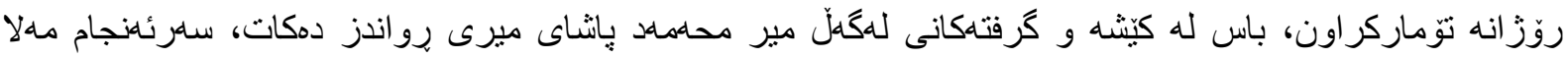

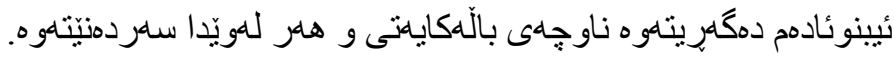

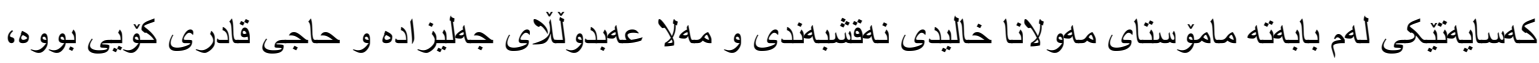

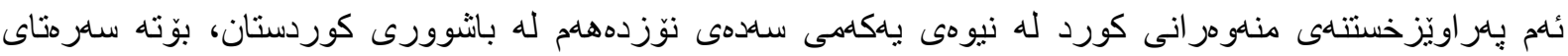

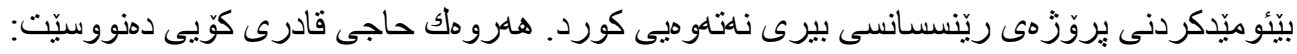
قوتبى زمانه خاليد ئاو اره بوو وهكوو من

$$
\text { بحئ قلهدر و قيمهت و شان، بـى خن و مان و بيّ نان }
$$

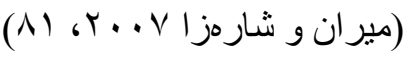

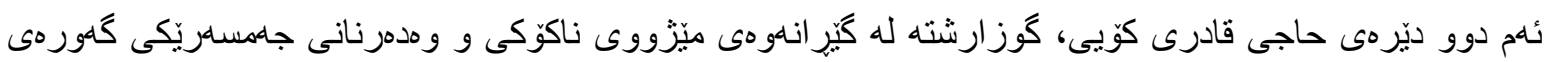

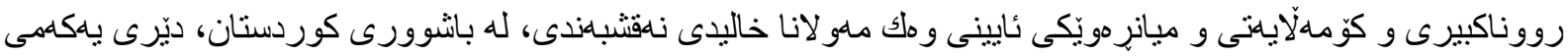

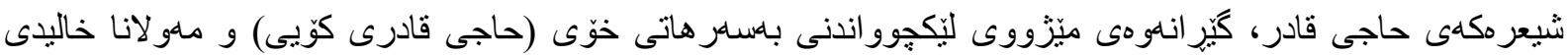

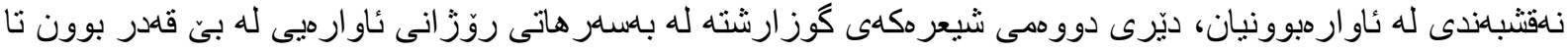

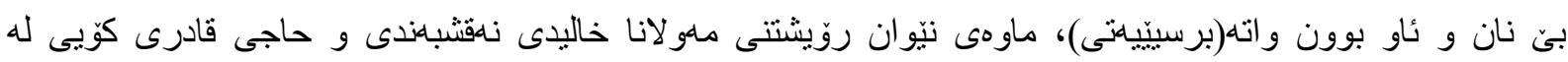

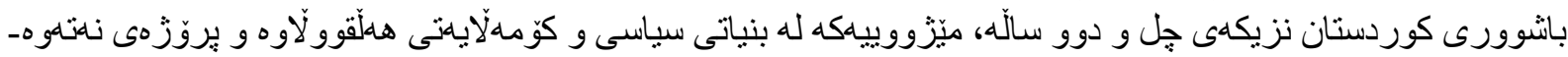

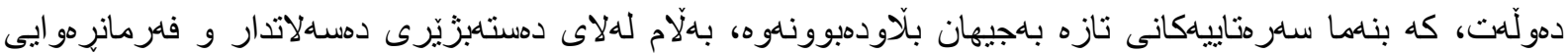

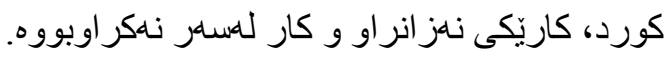

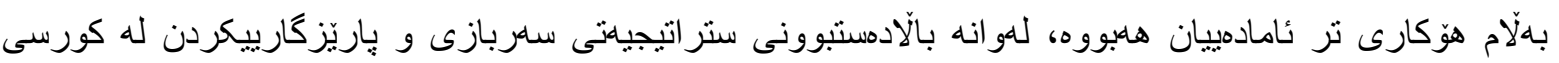

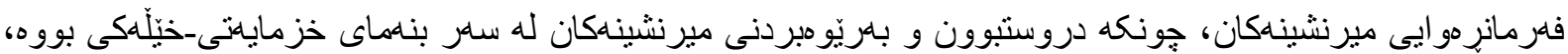

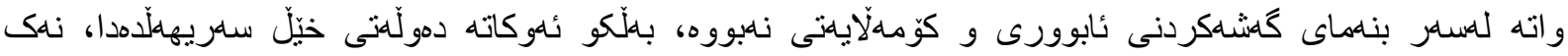

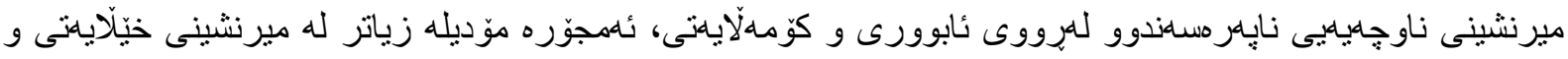

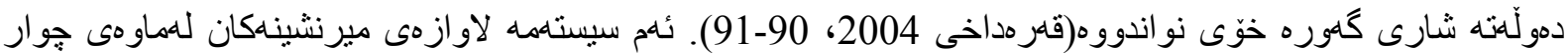

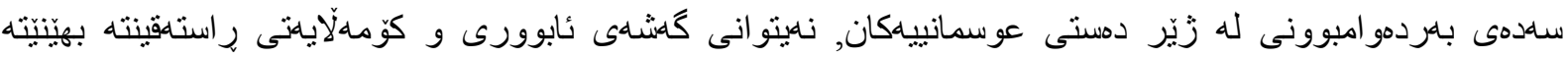

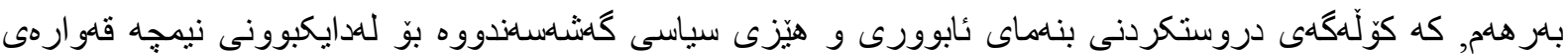

نانتهاو ميى.

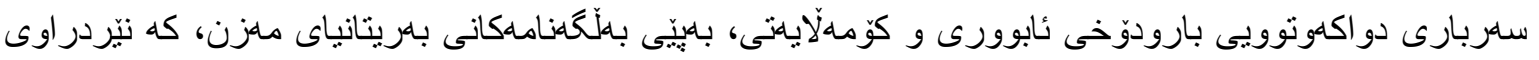

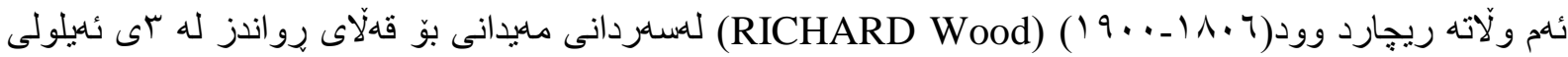

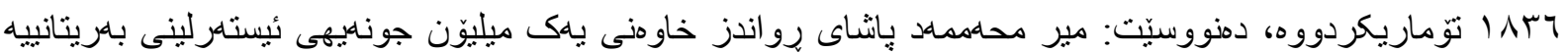

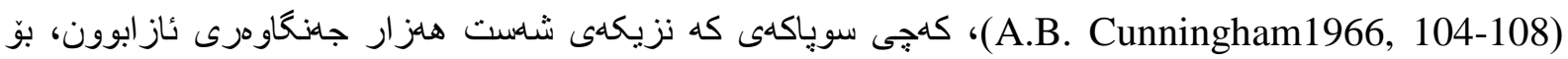

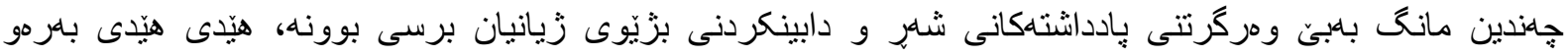

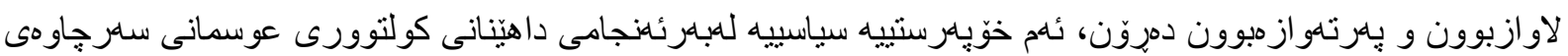

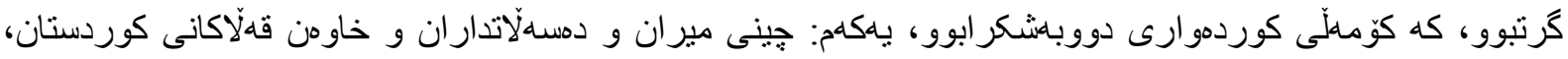

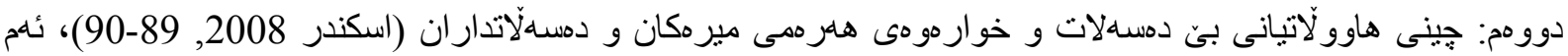

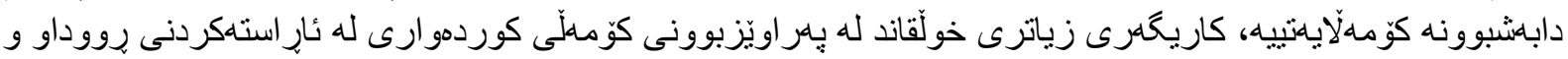




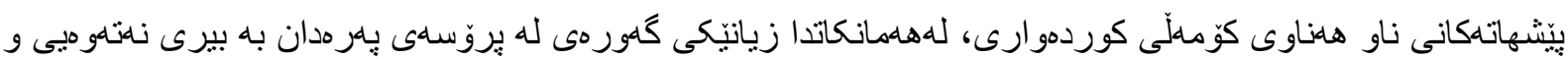

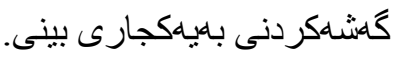

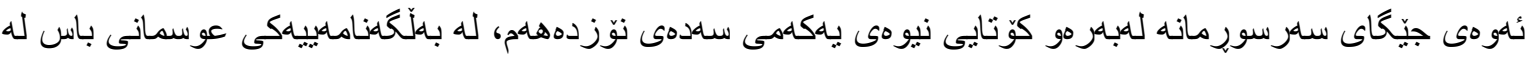

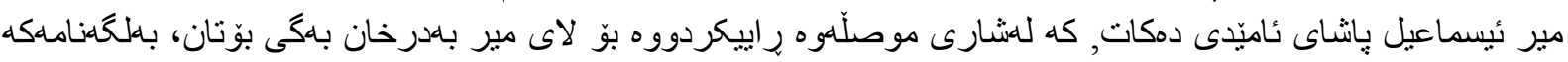

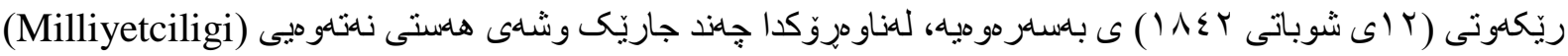

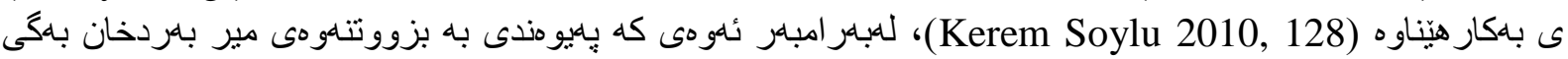

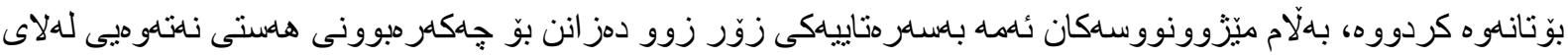

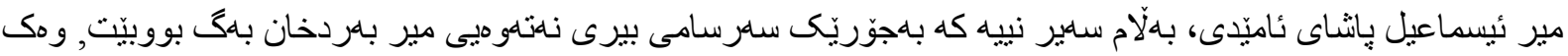

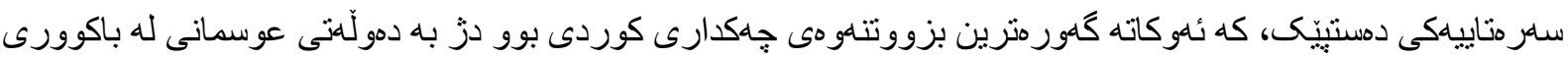

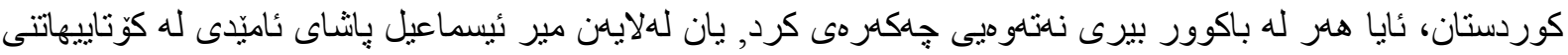

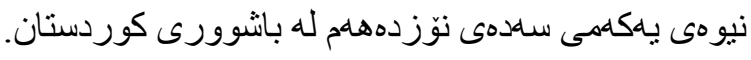

ئنانجام:

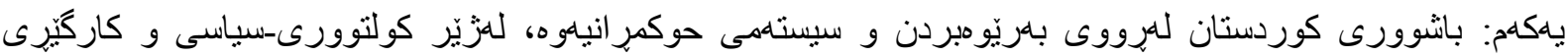

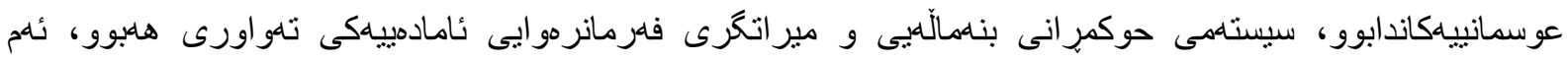

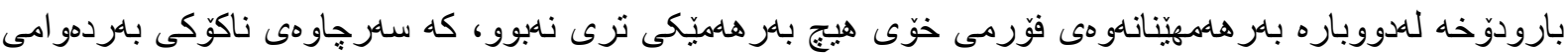

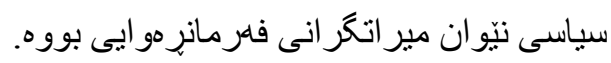

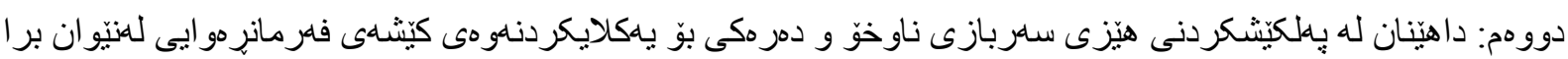

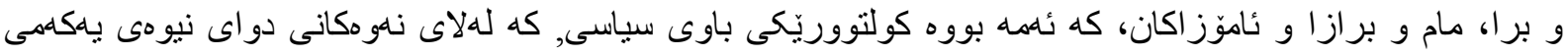

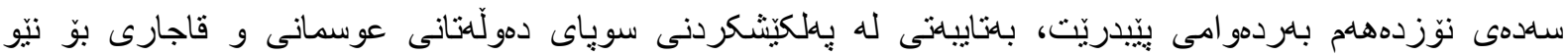
كوردستان.

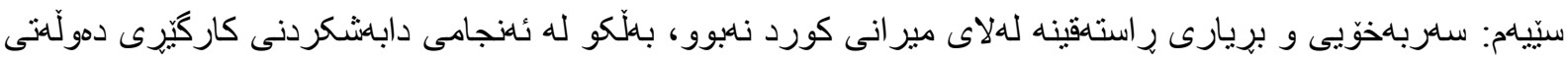

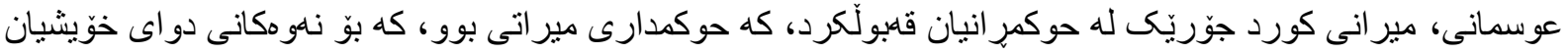

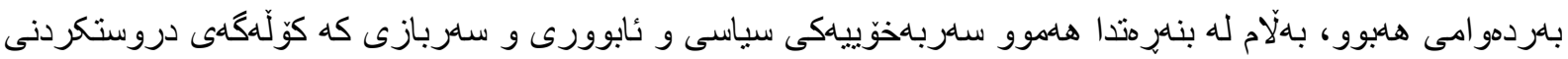

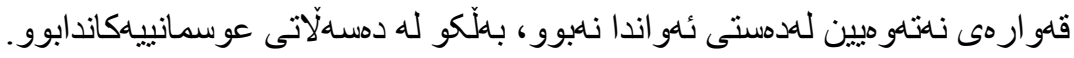

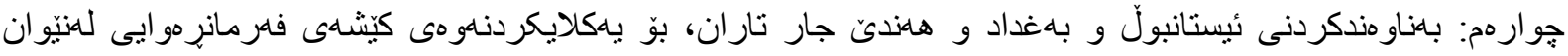

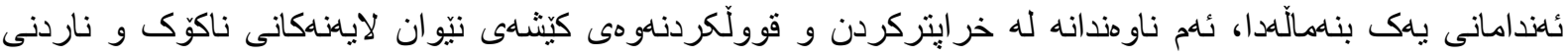

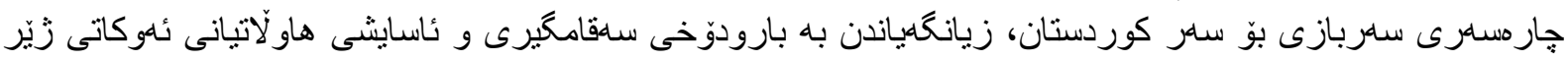
دمستى فهرمانير هو اييانى بابان و سوّر بان.

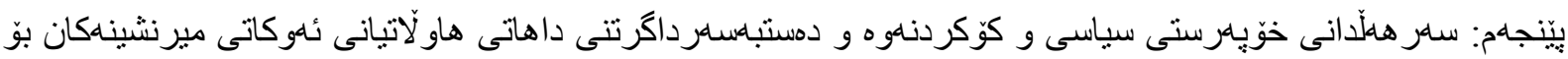

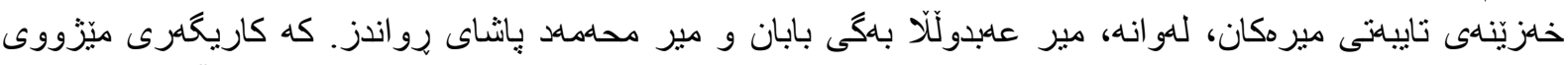

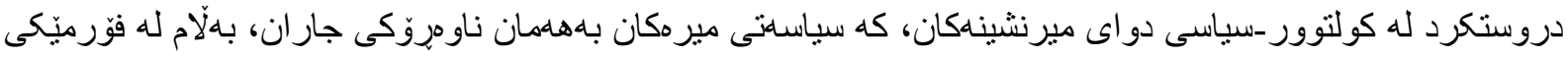
جياو ازدا بهردمو امى هلهبيّيت.

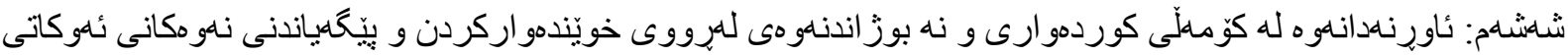

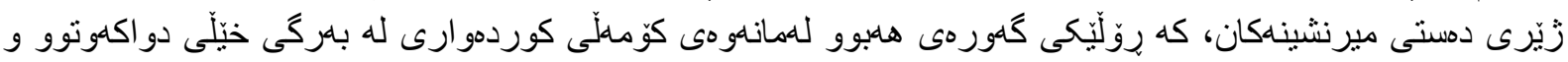

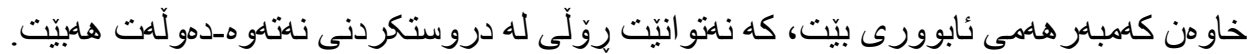




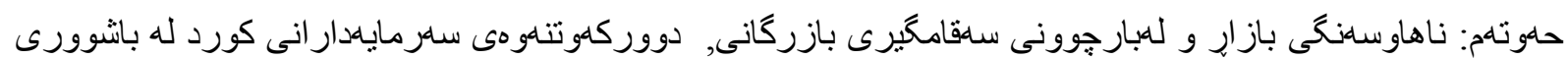

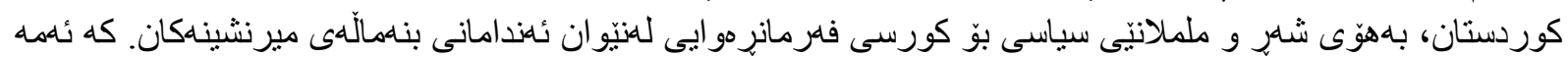

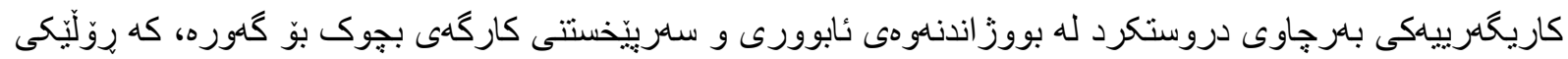

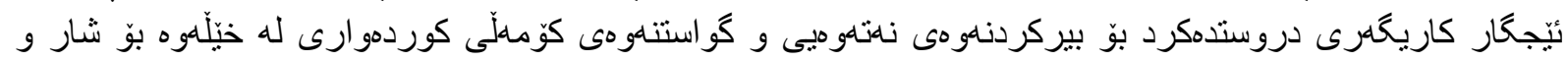

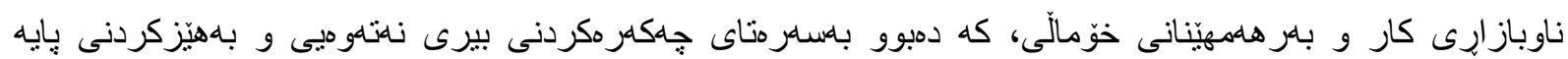

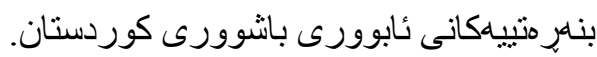

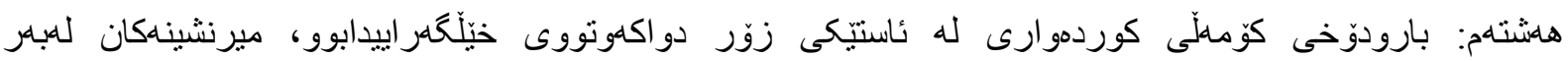

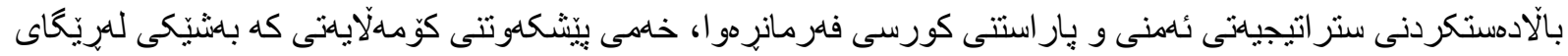

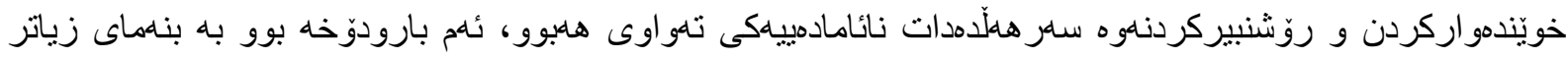

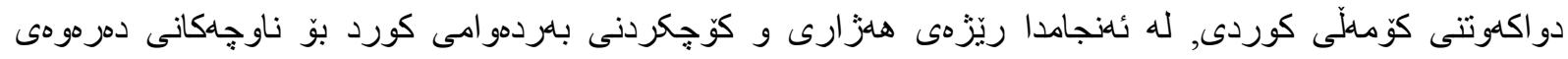

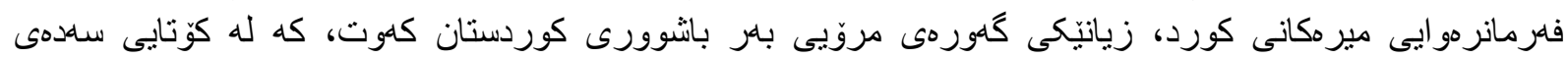

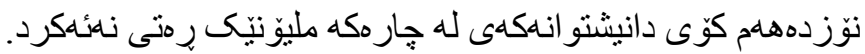

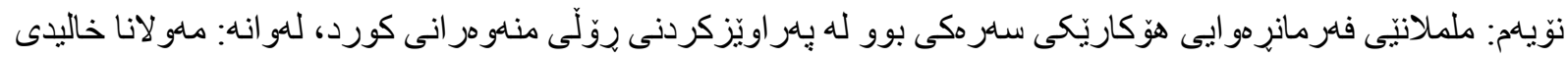

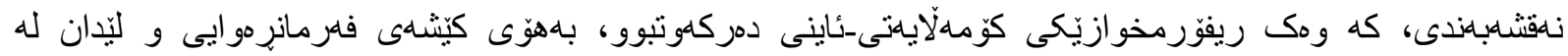

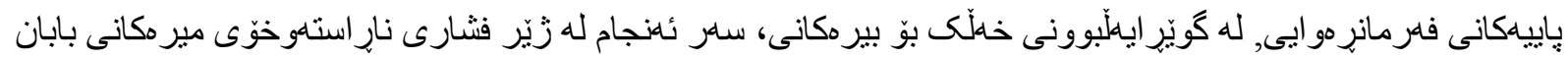

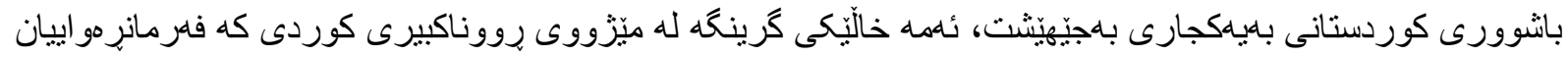

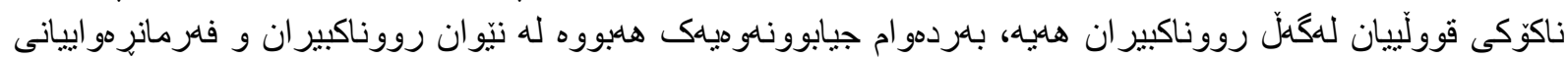

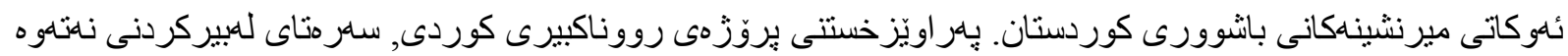

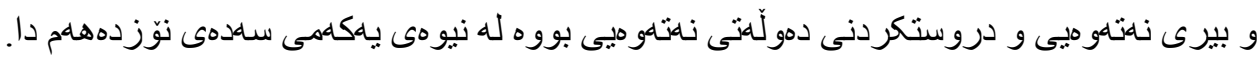

ليستى سدرجاوهكان

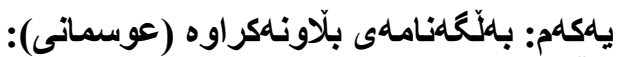

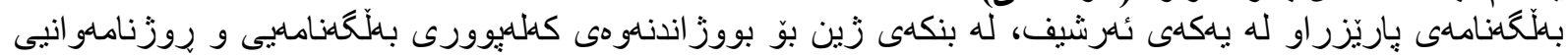

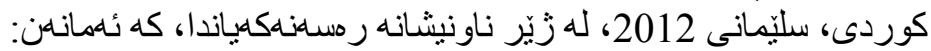

1-Basbakanlik Osmanli Arisivi: HAT: 0397/20899-D

2-Basbakanlik Osmanli Arisivi: HAT: 0797/36984:

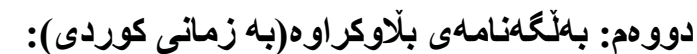

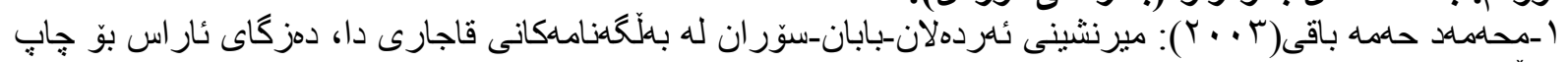

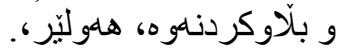

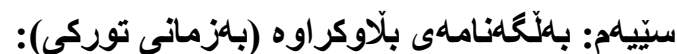
1-Kerem Soylu(2010): Mesail-I Muhimme-I Kurdistan(Kurdistanin Onemili Meseleleri Birinci Basim. Osmanlica ve Turkce)Enstituya Kurdi Ya Amede, Edubba, Diyarbakir,

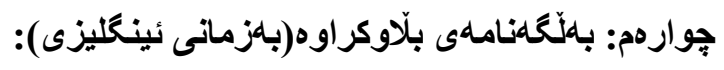

( ${ }^{1}$ A.B. Cunningham(1966): The Early Correspondence of Richard Wood 1831-1841,The Royal Historical Society, London, vol3. 


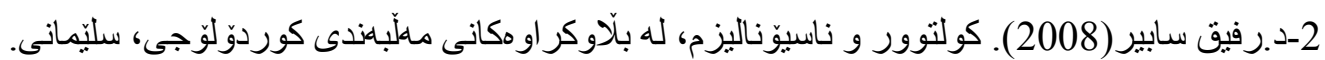

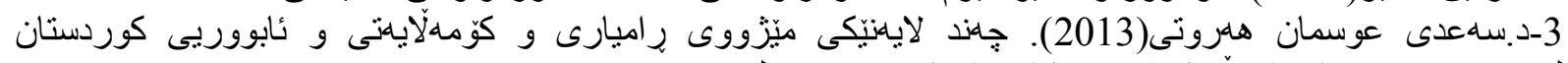

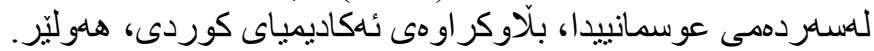

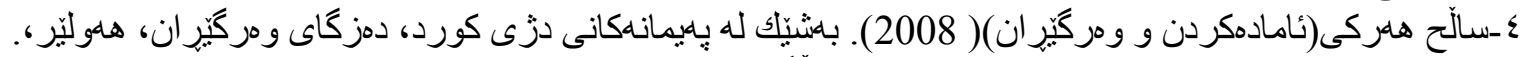

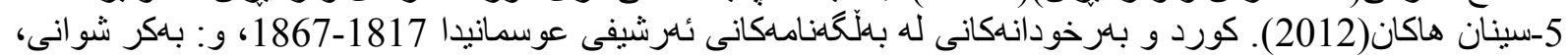

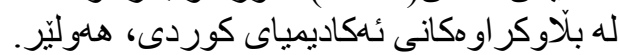

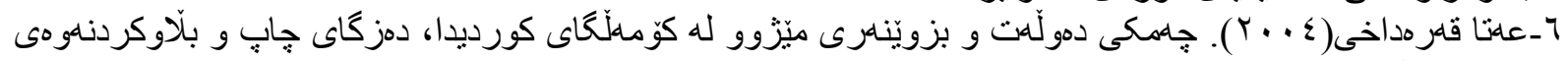

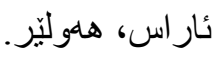

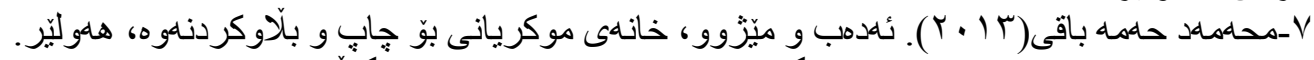

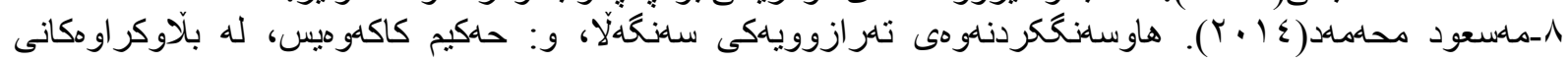

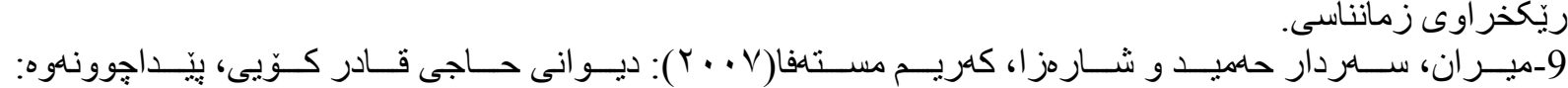

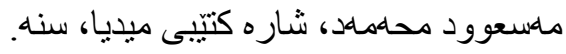

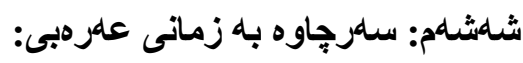

ا-د.خليل اينالجك(2002). تاريخ الدولة العثمانية من النشوء إلى الإنحدار، ت: د.محمد.م.الأرناؤوط، دار المدار

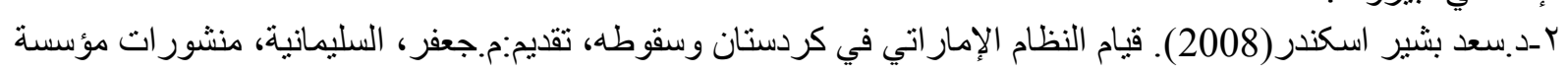

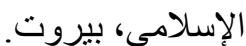
زين لإحياء التراث الوثائقي و الصحفي الكردي.

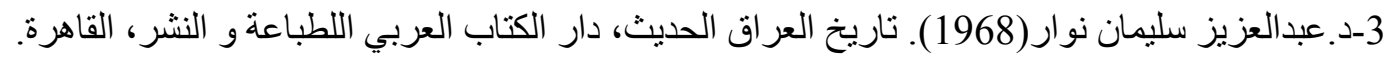

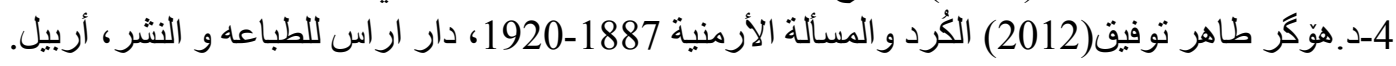
5ـ الأب بطرس حداد ( ترجمة و تعليق) (2011). رحلة دوبريه إلى العراق 1807-1809م، الثركة بيت الور اق للنشر

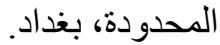

6-سليمان أبو عز الدين(2009). إبراهيم باثا في سوريا، تقديم و دراسة و مراجعة و تعليق: لطيفة محمد سالم، دار الثروق، القاهرة. 7-مؤلف مجهول(2010). روضة الكُة الأخبار في ذكر أفراد الأخبار، تحقيق: د.عماد عبدالسلام رؤوف، مؤسسة ذين لإحياء التزاث الوثائقي و الصحفي الكردي، السليمانية،

حهوتهم: نامه زانكوّييهكان(بلّاونهكراوهكان):

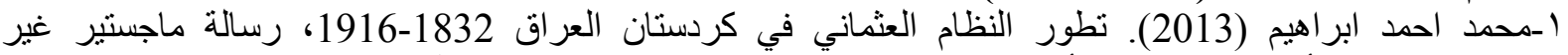

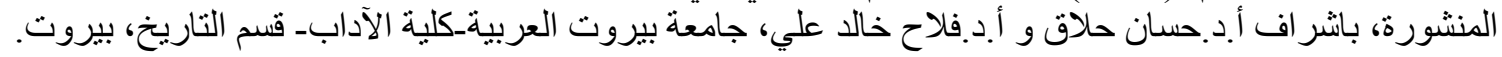

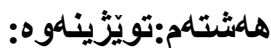

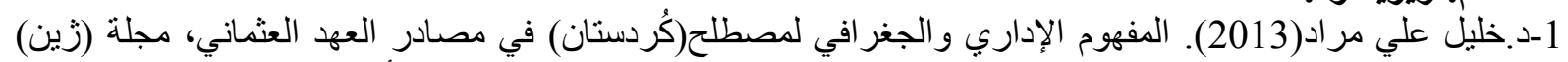

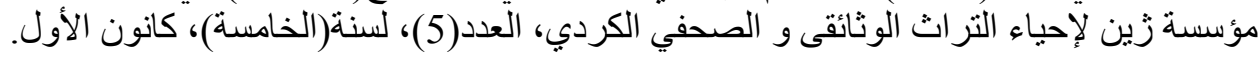

